\title{
The influence of grain morphology and easy axis orientation on the coercivity of $\operatorname{Sm}\left(\mathrm{Co}_{0.9} \mathrm{Cu}_{0.1}\right)_{5}$ thin films
}

\author{
W. B. Cui, L. Ma, H. Sepehri-Amin, Y. K. Takahashi and K. Hono* \\ National Institute for Materials Science, Tsukuba 305-0047, Japan
}

$\operatorname{Sm}\left(\mathrm{Co}_{0.9} \mathrm{Cu}_{0.1}\right)_{5}$ single-layer thin films and $\mathrm{Sm}\left(\mathrm{Co}_{0.9} \mathrm{Cu}_{0.1}\right)_{5} / \mathrm{Fe}_{2} \mathrm{Co}$ exchange coupled bilayer films with c-axis in the plane (IP) and out of the plane (OOP) orientations were prepared on $\mathrm{MgO}$ and $\mathrm{Al}_{2} \mathrm{O}_{3}$ single crystalline substrates by magnetron sputtering. Clear relationship between the grain morphology and coercivity was observed for the $\mathrm{Sm}\left(\mathrm{Co}_{0.9} \mathrm{Cu}_{0.1}\right)_{5}$ single-layer films. We found the thermal stability of coercivity is largely influenced by the c-axis orientation because the c-axis IP geometry lowers magnetostatic effect that plays an increasing role at elevated temperature. In $\mathrm{Sm}\left(\mathrm{Co}_{0.9} \mathrm{Cu}_{0.1}\right)_{5} / \mathrm{Fe}_{2} \mathrm{Co}$ bilayer films with the two c-axis geometries, the coercivity show larger dependence on the thickness of the $\mathrm{Fe}_{2} \mathrm{Co}$ layer for the c-axis IP geometry due to the energetically unfavorable magnetostatic coupling between hard/soft-magnetic layers, which is supported by micromagnetic simulations.

Keywords: permanet magnet, coercivity, $\mathrm{SmCo}_{5}$, micromagnetic, thin film

\footnotetext{
*Corresponding author: kazuhiro.hono@nims.go.jp 


\section{Introduction}

The development of high-performance permanent magnets for the traction motors of (hybrid) electric vehicles and wind turbines is receiving increasing interest. Commercial $\mathrm{Nd}-\mathrm{Fe}-\mathrm{B}$ based sintered magnets with moderate coercivity is demagnetized at operating temperature of around $200^{\circ} \mathrm{C}$ because of large demagnetization field in these applications unless ambient coercivity is improved to around $3 \mathrm{~T}$ by alloying heavy rare earth element (HREE) like Dy and Tb [1]. Some progresses have been made in enhancing the coercivity of bulk hot-deformed magnets by the eutectic diffusion process without HREE [2-5], in which the formation of Nd-rich intergranular phases is thought to be critical for achieving high coercivity. Liu et al [6] have shown a direct correlation between the Nd composition in the intergranular phases and the coercivity of hot-deformed magnets using three-dimensional atom probe. Cui et al [7] have shown that an ambient coercivity of $\sim 3 \mathrm{~T}$ can be achieved in an ultrafine grained model thin film by infiltrating a $\mathrm{Nd}-\mathrm{Cu}$ alloy in the grain boundaries without using Dy. In these thin films, the $\mathrm{Nd}_{2} \mathrm{Fe}_{14} \mathrm{~B}$ grains with average grain size of $\sim 50 \mathrm{~nm}$ are completely decoupled by the $\mathrm{Nd}-\mathrm{Cu}$ intergranular phase. The thermal stability of coercivity in the films was found to be substantially improved compared to the standard sintered magnets, which is attributed to the reduced magnetostatic field by the grain size reduction $[7,8]$. The coercivity enhancement in the eutectic diffusion processed $\mathrm{Nd}-\mathrm{Fe}-\mathrm{B}$ magnets have been attributed to the isolation of $\mathrm{Nd}_{2} \mathrm{Fe}_{14} \mathrm{~B}$ phase grains by the formation of $\mathrm{Nd}$-rich intergranular phase and the resultant reduction of intergranular exchange coupling [5]. However, such an explanation has not been confirmed because the isolated single $\mathrm{Nd}_{2} \mathrm{Fe}_{14} \mathrm{~B}$ grains or granular morphology are not easily realized in the Nd-Fe-B system.

The $\mathrm{SmCo}_{5}$ compound possesses huge uniaxial magnetocrystalline anisotropy $\left(K_{\mathrm{u}} \sim 17.2\right.$ $\left.\mathrm{MJ} / \mathrm{m}^{3}\right)$ and anisotropy field $\left(\mu_{0} H_{\mathrm{A}} \sim 35 \mathrm{~T}\right)$, so it can generate large coercivity if crystal grains 
are magnetically isolated in thin films $[9,10]$. Another merit of $\mathrm{SmCo}_{5}$-based thin films is that the easy axis (c-axis) can be manipulated by using different substrates. The c-axis in-plane (IP) geometry was reported in the films epitaxially grown on $\mathrm{MgO}(110)$ single crystal substrates with $\mathrm{W}$ [11] and $\mathrm{Cr}$ [12] buffer layers. The c-axis out-of-plane (OOP) geometry was realized by growing $\mathrm{SmCo}_{5}$ films on $\mathrm{Al}_{2} \mathrm{O}_{3}(001)$ single-crystal substrates with $\mathrm{Ru}$ buffer layers [13]. The different c-axis geometry with respect to the film plane would cause a significant difference on magnetostatic field. Therefore, $\mathrm{SmCo}_{5}$-based thin film with different morphologies and c-axis geometries can be used as a good model to study how the morphologies of hard-magnetic phase and magnetostatic field influence the coercivity.

The exchange-spring principle [14] was proposed to be a promising way to achieve higher maximum energy product, $(B H)_{\max }$, in nanocomposite magnets [15]. Since then, many experimental and theoretical works on geometry optimization or "rational design" of hard/soft nanostructure have been carried out. A variety of geometries such as embedded soft cylinders [16], cubic [17] and disordered nanostructures [15,18] were studied by micromagnetic simulations [19]. These different coupling geometries promoted the fundamental understandings on exchange coupling between soft/hard magnetic phases. Some progresses were achieved in the $\mathrm{SmCo}_{5} / \mathrm{Fe}$ multilayer geometry with c-axis of $\mathrm{SmCo}_{5}$ phase along the in-plane direction $[20,21]$. However, up to now, experimental evidence is still not sufficient to demonstrate which c-axis geometry is beneficial for higher coercivity in exchange coupled magnets.

In this paper, different morphologies and c-axis geometries of $\operatorname{Sm}\left(\mathrm{Co}_{0.9} \mathrm{Cu}_{0.1}\right)_{5}(50 \mathrm{~nm})$ single-layer (SL) films and $\operatorname{Sm}\left(\mathrm{Co}_{0.9} \mathrm{Cu}_{0.1}\right)_{5} / \mathrm{Fe}_{2} \mathrm{Co}$ exchange coupled bi-layer films were fabricated in order to investigate the effects of easy axis orientations on the coercivities and their thermal stabilities. The reason why we selected $\mathrm{Sm}\left(\mathrm{Co}_{0.9} \mathrm{Cu}_{0.1}\right)_{5}$ in stead of $\mathrm{SmCo}_{5}$ as 
hard magnetic phase for this experiment is based on our earlier work on the $\mathrm{Sm}\left(\mathrm{Co}_{0.9} \mathrm{Cu}_{0.1}\right)_{5} / \mathrm{FeCo}$ exchange coupled films, in which higher coercivity can be attained compared to the $\mathrm{Cu}$-free system [22,23] because of enhanced anisotropy field [24]. Although

the coercivities for the IP and OOP geometries are nearly the same, the thermal stability of coercivity is substantially improved in the OOP geometry due to reduced magnetostatic field. Then, $\operatorname{Sm}(\mathrm{Co}, \mathrm{Cu})_{5}(50 \mathrm{~nm}) / \mathrm{Fe}_{2} \mathrm{Co}(x \mathrm{~nm})(x=0,3,5,8$ and $10 \mathrm{~nm})$ bilayer films were prepared with different c-axis geometry. Our experiments demonstrated that c-axis OOP geometry in $\mathrm{Sm}(\mathrm{Co}, \mathrm{Cu})_{5}$ layer leads to higher coercivity due to stronger hard/soft exchange coupling, which was further confirmed by micromagnetic simulations.

\section{Experimental}

$\operatorname{Sm}\left(\mathrm{Co}_{0.9} \mathrm{Cu}_{0.1}\right)_{5}(50 \mathrm{~nm})$ single layer films with c-axis IP (or OOP) geometry were prepared by co-sputtering $\mathrm{Sm}(99.5 \%), \quad \mathrm{Co}(99.9 \%), \quad \mathrm{Cu}(99.9 \%)$ targets onto $\mathrm{Cr}\left(20 \mathrm{~nm}\right.$ )-buffered $\mathrm{MgO}(110)$ (or $\mathrm{Ru}\left(20 \mathrm{~nm}\right.$ )-buffered $\mathrm{Al}_{2} \mathrm{O}_{3}(012)$ ) single-crystal substrates respectively. The base vacuum was higher than $10^{-6} \mathrm{~Pa}$ and the Ar pressure for sputtering was $0.6 \mathrm{~Pa}$. All substrates were thermally cleaned at $600^{\circ} \mathrm{C}$ for $1 \mathrm{~h}$. The composition of $\mathrm{Sm}(\mathrm{Co}, \mathrm{Cu})_{5}$ thin films was optimized first. In $\mathrm{Cu}$-free $\mathrm{SmCo}_{5}$ thin film, the coercivity was very low with poor squareness. Minor amount of $\mathrm{Cu}$ addition stabilized the 1:5 phase, leading to high coercivity and good squareness. While, too high $\mathrm{Cu}$ addition caused the reduction of magnetization and coercivity. Therefore, $\operatorname{Sm}\left(\mathrm{Co}_{0.9} \mathrm{Cu}_{0.1}\right)_{5}$ was selected as the thin film composition. The films were mainly composed of the $\mathrm{SmCo}_{5}$ phase, so the films are hereafter designated as $\mathrm{Sm}\left(\mathrm{Co}_{0.9} \mathrm{Cu}_{0.1}\right)_{5} . \mathrm{Sm}\left(\mathrm{Co}_{0.9} \mathrm{Cu}_{0.1}\right)_{5}(50 \mathrm{~nm})$ layers were first deposited onto $\mathrm{Cr}(20 \mathrm{~nm})$-buffered $\mathrm{MgO}(110)$ substrate at $450^{\circ} \mathrm{C}$ or $350^{\circ} \mathrm{C}$ to achieve different morphologies with c-axis IP geometry (denoted as film 1 and film 2). $\mathrm{Sm}\left(\mathrm{Co}_{0.9} \mathrm{Cu}_{0.1}\right)_{5}(50 \mathrm{~nm})$ layers were 
then deposited onto $\mathrm{Ru}(20 \mathrm{~nm})$-buffered $\mathrm{Al}_{2} \mathrm{O}_{3}(012)$ substrate at $350^{\circ} \mathrm{C}$ to achieve c-axis OOP geometry (denoted as film 3). $\operatorname{Cr}(20 \mathrm{~nm})$ capping layer was used in film 1 and film 2 and $\mathrm{Ru}(20 \mathrm{~nm})$ capping layer was used in film 3. After deposition, the films were then annealed at $450^{\circ} \mathrm{C}$ for $30 \mathrm{~min}$. Based on film 2 and film 3, $\mathrm{Sm}\left(\mathrm{Co}_{0.9} \mathrm{Cu}_{0.1}\right)_{5}(50 \mathrm{~nm}) / \mathrm{Fe}_{2} \mathrm{Co}(x \mathrm{~nm})$ exchange coupled bilayer films were prepared with c-axis IP or OOP. $\mathrm{Fe}_{2} \mathrm{Co}(x \mathrm{~nm})$ layer were deposited near room temperature to avoid the interface diffusion. The constituent phases were characterized by X-ray diffraction (XRD) using $\mathrm{Cu} \mathrm{K}_{\alpha}$ radiation. The hysteresis loops along the perpendicular and parallel directions were measured by the SQUID vibrating sample magnetometer (VSM) with a maximum applied field of $7 \mathrm{~T}$. The microstructures were characterized by Tecnai F20 and Titan G2 80-200. In the micromagnetic simulation of $\operatorname{Sm}\left(\mathrm{Co}_{0.9} \mathrm{Cu}_{0.1}\right)_{5}(50 \mathrm{~nm}) / \mathrm{Fe}_{2} \mathrm{Co}(x \mathrm{~nm})(\mathrm{x}=0,3,5,8$ and $10 \mathrm{~nm})$ exchange coupled films, tetrahedron meshes were applied on the models with a maximum size of $2 \mathrm{~nm}$ and the Landau-Lifshitz-Gilbert (LLG) equation at each node was solved by the FEMME software [25]. The magnetocrystalline anisotropy $\left(K_{\mathrm{u}}\right)$, saturation magnetization $\left(\mu_{0} M_{\mathrm{s}}\right)$ and exchange stiffness were $17 \mathrm{MJ} / \mathrm{m}^{3}, 1.0 \mathrm{~T}$ and $8.6 \mathrm{pJ} / \mathrm{m}$ for $\operatorname{Sm}\left(\mathrm{Co}_{0.9} \mathrm{Cu}_{0.1}\right)_{5}$ phase and $0.0 \mathrm{MJ} / \mathrm{m}^{3}, 2.45 \mathrm{~T}$ and $22 \mathrm{pJ} / \mathrm{m}$ for $\mathrm{Fe}_{2} \mathrm{Co}$ phase [7-10].

\section{Results}

Figure 1 shows the X-ray diffraction patterns of $\mathrm{MgO} / \mathrm{Cr}(20 \mathrm{~nm}) / \mathrm{Sm}\left(\mathrm{Co}_{0.9} \mathrm{Cu}_{0.1}\right)_{5}(50$ $\mathrm{nm}) / \mathrm{Cr}\left(20 \mathrm{~nm}\right.$ ) film deposited at (a) $450^{\circ} \mathrm{C}$ (film 1) and (b) $350^{\circ} \mathrm{C}$ (film 2), and (c) $\mathrm{Al}_{2} \mathrm{O}_{3} / \mathrm{Ru}(20 \mathrm{~nm}) / \mathrm{Sm}\left(\mathrm{Co}_{0.9} \mathrm{Cu}_{0.1}\right)_{5}(50 \mathrm{~nm}) / \mathrm{Ru}(20 \mathrm{~nm})$ film (film 3) deposited at $350^{\circ} \mathrm{C}$. In Fig. 1a and $1 \mathrm{~b}$, the strong $\operatorname{Cr}(211)$ peaks are observed at $2 \theta=81.7^{\circ}$. The peaks at $2 \theta=20.4^{\circ}, 41.5^{\circ}$ and $90.4^{\circ}$ correspond to the (100), (200) and (400) planes of the $\operatorname{Sm}\left(\mathrm{Co}_{0.9} \mathrm{Cu}_{0.1}\right)_{5}$ phase, which suggests the c-axis IP geometry on Cr-buffered $\mathrm{MgO}(110)$ substrates. On the other hand, in 
Fig. 1c, strong peaks at $2 \theta=42.3^{\circ}$ and $92.4^{\circ}$ are from the (002) and (004) planes of the $\mathrm{Ru}$ buffer layer. Minor peak at $2 \theta=38.5^{\circ}$ is for $\operatorname{Ru}(100)$ plane. While strong peaks of $(001),(002)$ and (003) plane of the $\operatorname{Sm}\left(\mathrm{Co}_{0.9} \mathrm{Cu}_{0.1}\right)_{5}$ phase can be observed, indicating the c-axis OOP geometry. The results indicate that the c-axis geometry of the $\operatorname{Sm}\left(\mathrm{Co}_{0.9} \mathrm{Cu}_{0.1}\right)_{5}$ phase can be manipulated to be along IP direction or OOP direction by using $\mathrm{MgO}(110)$ and $\mathrm{Al}_{2} \mathrm{O}_{3}(012)$ substrates.

The corresponding hysteresis loops are shown in Fig. 2. In Fig. 2a and Fig. 2b, high coercivity of $3.7 \mathrm{~T}$ and $3.24 \mathrm{~T}$ are achieved, respectively. Good squareness is realized along the IP direction and magnetization is hard to be saturated along the OOP direction with narrow hysteresis, magnetically verifying the c-axis IP geometry in Film 1 and Film 2. On the other hand, high squareness is achieved along the OOP direction with narrow hysteresis along the IP direction for Film 3 that was grown on a $\mathrm{Al}_{2} \mathrm{O}_{3}$ substrate. A high coercivity of $3.56 \mathrm{~T}$ is comparable with those in Film 1 and Film 2, showing strong perpendicular anisotropy. Note that the coercivity of $3.56 \mathrm{~T}$ in the present work is one of the highest reported coercivity in Sm-Co films with strong perpendicular anisotropy $[13,26]$, even as high as FePt-C system [27]. The saturation in the thin films with c-axis IP geometry is different with that of OOP case. One reason is thought to be because of the epitaxial growth quality. As seen the XRD patterns of film 3, the disorientation of $\mathrm{Ru}$ underlayer will lead to the misalignment of c-axis in $\mathrm{Sm}\left(\mathrm{Co}_{0.9} \mathrm{Cu}_{0.1}\right)_{5}$ phase. Another reason may be due to the existence of secondary nonmagnetic impurities.

Figure 3 compares the cross-sectional morphologies of these three films. Fig. 3a shows the granular morphology in Film 1 because deposition temperature was as high as $450^{\circ} \mathrm{C}$. In each island-like particle, several grains are contained. Fig. $3 \mathrm{~b}$ and Fig. $3 \mathrm{c}$ display the cross-sectional morphologies of Film 2 along the [001] and [110] zone axes of the $\mathrm{MgO}$ 
substrates, whose nano beam electron diffraction patterns (NBEDP) are shown in Fig. 3e and Fig. 3g. Continuous structure is observed for Film 2. Fig 3e reveals that the $\mathrm{MgO}[001]$ direction and [1 $\overline{10}$ ] direction are parallel to the surface of $\mathrm{MgO}$ substrate whose normal direction is $[\overline{1} 10]$, which is consistent with the diffraction patterns shown in Fig. 3g. Fig. $3 \mathrm{f}$ shows the diffraction pattern of $\operatorname{Sm}\left(\mathrm{Co}_{0.9} \mathrm{Cu}_{0.1}\right)_{5}$ layer in Fig. 3b taken along the [001] zone axis of the $\mathrm{MgO}$ substrate. A six-fold symmetry is observed, which is indexed as $\operatorname{Sm}\left(\mathrm{Co}_{0.9} \mathrm{Cu}_{0.1}\right)_{5}(0001)$ plane. From Fig. 3e and Fig.3f, the orientation relationship between the $\mathrm{MgO}$ substrate and the $\mathrm{Sm}\left(\mathrm{Co}_{0.9} \mathrm{Cu}_{0.1}\right)_{5}$ phase can be described as $\mathrm{MgO}[001](110) / /$ $\mathrm{Sm}\left(\mathrm{Co}_{0.9} \mathrm{Cu}_{0.1}\right)_{5}[0001](01 \overline{1} 0)$ and $\mathrm{MgO}[001](1 \overline{1} 0) / / \mathrm{Sm}\left(\mathrm{Co}_{0.9} \mathrm{Cu}_{0.1}\right)_{5}[00 \overline{1}](2 \overline{1} \overline{1} 0)$. Fig. $3 \mathrm{~h}$ shows NBEDP of $\mathrm{Sm}\left(\mathrm{Co}_{0.9} \mathrm{Cu}_{0.1}\right)_{5}$ layer in Fig. $3 \mathrm{~b}$ taken along the [110] zone axis of the $\mathrm{MgO}$ substrate. A two-fold symmetry is found in Fig.3h, which is obtained by viewing along [10 $\overline{1} 0]$ zone axis of the $\operatorname{Sm}\left(\mathrm{Co}_{0.9} \mathrm{Cu}_{0.1}\right)_{5}$ phase. The orientation relationship between the $\mathrm{MgO}$ substrate and the $\mathrm{Sm}\left(\mathrm{Co}_{0.9} \mathrm{Cu}_{0.1}\right)_{5}$ phase can be described as $\mathrm{MgO}[110](001) / / \mathrm{Sm}\left(\mathrm{Co}_{0.9} \mathrm{Cu}_{0.1}\right)_{5}$ $[10 \overline{1} 0](0001)$ and $\mathrm{MgO}[110](\overline{1} 10) / / \mathrm{Sm}\left(\mathrm{Co}_{0.9} \mathrm{Cu}_{0.1}\right)_{5}[10 \overline{1} 0](01 \overline{1} 0)$. The cross-sectional TEM image of Film 3 is shown in Fig. 3d. The nanosized Ru grains are observed in the under layer and cover layer. The surface of the $\operatorname{Sm}\left(\mathrm{Co}_{0.9} \mathrm{Cu}_{0.1}\right)_{5}$ layer is very rough, which is one reason for the observed $\mathrm{Ru}(100)$ peak in the XRD pattern (Fig. 1c). The columnar $\operatorname{Sm}\left(\mathrm{Co}_{0.9} \mathrm{Cu}_{0.1}\right)_{5}$ grains with average grain size of $50 \mathrm{~nm}$ are formed with c-axis OOP. Lamella-like contrasts are seen in these columnar grains (as marked in Fig. 3d), which is due to the stacking faults within c-plane of the $\mathrm{Sm}\left(\mathrm{Co}_{0.9} \mathrm{Cu}_{0.1}\right)_{5}$ grains.

HAADF-STEM images taken along the [0001] and [10 $\overline{1} 0]$ zone axis of the $\operatorname{Sm}\left(\mathrm{Co}_{0.9} \mathrm{Cu}_{0.1}\right)_{5}$ phase are shown in Fig. $4 \mathrm{a}$ and $4 \mathrm{~b}$. In the top region of Fig. $4 \mathrm{a}$, six nearest dots surround a dot with uniform size and contrast forming a hexagon, which is schematically shown in the right-top inset to Fig. 4a. The atomic configuration is different in the bottom 
region of Fig. 4a. Outside a large-size dot, there are two sets of hexagons. The inner set of hexagon contains six small-size dots with weak contrast and the outer set of hexagon contains six dots with the same size and contrast, which is schematically displayed in the right-down inset to Fig. 4a. Since the contrast in the HAADF image is proportional to the square of the atomic number, the large-size dots with strong contrast correspond to Sm atom columns and the small-size dots with weak contrast correspond to the atomic column with a mixture of $\mathrm{Cu}$ and Co atoms. The averaged contrast and size in the top region of Fig. $4 \mathrm{a}$ are due to the overlapping of $\mathrm{Sm}$ atoms and $\mathrm{Co} / \mathrm{Cu}$ atoms, which is caused by the stacking faults. It is further confirmed by the HAADF-STEM image viewing down along [10피 zone axis of the $\mathrm{Sm}\left(\mathrm{Co}_{0.9} \mathrm{Cu}_{0.1}\right)_{5}$ phase as shown in Fig. 4b. Many stacking faults are observed as marked. The interface atomic occupations are displayed in the inset to Fig 4b. Stacking structure is schematically shown in Fig. 4c. It is clear that the displacements are along the [11 $\overline{2} 0]$ direction. One displacement causes $0.144 \mathrm{~nm}$ of atomic terrace height as marked in Fig. 4c, which is consistent with the atomic terrace height observed in Fig. $4 \mathrm{~b}$ considering $\mathrm{Cu}$ substitution for Co. After three displacements, the $\mathrm{Sm}$ atoms will be superimposed with $\mathrm{Co} / \mathrm{Cu}$ atoms, forming a miniaturized hexagon as indicated by the black dots in Fig. 4c, leading to uniform size and contrast as observed by HAADF-STEM in Fig. 4a. So the displacement vector is $1 / 3$ [11 $\overline{2} 0]$.

The temperature dependence of coercivity of these films is shown in Fig. 5. At room temperature, the coercivity of $3.7 \mathrm{~T}$ was achieved in Film 1, which is higher than those in Film 2 and Film 3. With increasing temperature, the coercivities in these films monotonously decrease due to the reduction in magnetocrystalline anisotropy. Compared with Film 3, the coercivity decreases slowly in Film 1 and 2 . Generally, the coercivity temperature coefficient $\beta$ is used to describe the thermal stability of coercivity and expressed as $\beta=\left[H_{c}\left(T_{2}\right)\right.$ - 
$\left.H_{c}\left(T_{1}\right)\right] /\left[H_{c}\left(T_{1}\right)\left(T_{2}-T_{1}\right)\right]$. Here, $H_{c}\left(T_{2}\right)$ and $H_{c}\left(T_{1}\right)$ are the coercivities at temperature $T_{2}$ $(=400 \mathrm{~K})$ and $T_{l}(=300 \mathrm{~K}) . \beta$ values for Film 1 and Film 2 were $-0.31 \% / \mathrm{K}$ and $-0.29 \% / \mathrm{K}$, respectively. In contrast, $\beta$ is decreased to $-0.42 \% / \mathrm{K}$ in Film 3 . Note that $\mathrm{c}$-axis is IP in Film 1 and Film 2 and it is OOP in Film 3. Hence, the higher $\beta$ achieved in Film 1 and Film 2 suggests that better thermal stability of coercivity is for the c-axis IP geometry.

The morphology changes including the c-axis geometries in Films $1-3$ are schematically illustrated in Fig. 6. C-axis is along the IP direction for both Film 1 and Film 2. Granular morphology and isolated particles in Film 1 cause magnetic isolation of the $\mathrm{Sm}\left(\mathrm{Co}_{0.9} \mathrm{Cu}_{0.1}\right)_{5}$ grains, leading to the higher coercivity of $3.7 \mathrm{~T}$ in Film 1 than $3.24 \mathrm{~T}$ in Film 2 , where there is a continuous microstructure with connected grains as schematically shown in Fig. 6a and Fig. 6b. When the c-axis is changed from the IP geometry in Film 2 to the OOP geometry in Film 3, $\beta$ is substantially lowered or the coercivity temperature dependence was degraded, which is ascribed to increased magnetostatic effect. At elevated temperature, magnetocrystalline anisotropy is decreased. Then, the magnetostatic field will assist the magnetization reversal, leading to steeper coercivity decrease as function of temperature, resulting in increase in $\beta$ for the c-axis OOP geometry. The role of magnetostatic field can also be supported by comparing $\beta$ in Film 1 and Film 2. Granular morphology leads to large local magnetostatic field in Film 1 , thereby degrading $\beta$ in Film 1 although the highest coercivity is achieved in Film 1. The micromagnetic model [28] correlates the coercivity $H_{c}$ with anisotropy field $H_{A}$ and saturation magnetization $\mu_{0} M_{S}$ by introducing temperature independent parameter $\alpha$ and $N_{\text {eff }}$ in the form of the following equations [30]:

$$
\mu_{0} H_{c}(T)=\alpha \mu_{0} H_{A}(T)-N_{\text {eff }} \mu_{0} M_{s}(T)
$$

By linear fitting experimentally measured $H_{\mathrm{c}}(T) / M_{\mathrm{s}}(T)$ and $H_{\mathrm{A}}(T) / M_{\mathrm{s}}(T), \alpha$ and $N_{\text {eff }}$ of Film 1 3 are deduced as shown in Fig. 6. Small $\alpha=0.14$ and $\alpha=0.07$ are obtained in Film 1 and Film 
2 as reported in ref. [12]. Small $N_{\text {eff }}$ are achieved in Film 1 and Film 2 with c-axis IP, compared with the significantly increased $N_{\text {eff }}$ in Film 3. Such dependence of $N_{\text {eff }}$ on c-axis geometry is qualitatively in agreement with the fact that higher magnetostatic field is expected in Film 3, indicating the critical role of magnetostatic field. The result is consistent with that found in the Nd-Fe-B thin film system that coercivity can be increased by magnetically isolating grains [7]. It is also demonstrated that the thermal stability of coercivity can be improved by reducing the magnetostatic effect.

The magnetic properties of hard- and soft-magnetic nanocomposite films are also believed to be strongly influenced by the c-axis geometry in the hard-magnetic layers. In order to figure out the optimized geometries, based on Film 2 and Film 3, two series of nanocomposite films were fabricated with film structures of $\mathrm{MgO} / \mathrm{Cr}(20 \mathrm{~nm}) /$ $\mathrm{Sm}\left(\mathrm{Co}_{0.9} \mathrm{Cu}_{0.1}\right)_{5}(50 \mathrm{~nm}) / \mathrm{Fe}_{2} \mathrm{Co}(\mathrm{x} \mathrm{nm}) / \mathrm{Cr}(20 \mathrm{~nm})$ and $\mathrm{Al}_{2} \mathrm{O}_{3} / \mathrm{Ru}(20 \mathrm{~nm}) / \mathrm{Sm}\left(\mathrm{Co}_{0.9} \mathrm{Cu}_{0.1}\right)_{5}(50$ $\mathrm{nm}) / \mathrm{Fe}_{2} \mathrm{Co}(\mathrm{x} \mathrm{nm}) / \mathrm{Ru}(20 \mathrm{~nm})$. The XRD patterns of these two films are shown in Fig. 7. From the (100), (101), and (200) peaks in Fig. 7a and the (001), (002) and (003) peaks in Fig.7b, it is observed that c-axis IP and OOP geometries are observed in the former and latter nanocomposite films. The corresponding hysteresis loops are shown in Fig. 8. The IP and OOP hysteresis loops indicate the c-axis geometries consistent with that observed from XRD results. In the $\mathrm{MgO} / \mathrm{Cr}(20 \mathrm{~nm}) / \mathrm{Sm}\left(\mathrm{Co}_{0.9} \mathrm{Cu}_{0.1}\right)_{5}(50 \mathrm{~nm}) / \mathrm{Fe}_{2} \mathrm{Co}(10 \mathrm{~nm}) / \mathrm{Cr}(20 \mathrm{~nm})$ film, the demagnetization process is continuous along both IP and OOP directions as shown in Fig. 8d. In the $\mathrm{Al}_{2} \mathrm{O}_{3} / \mathrm{Ru}(20 \mathrm{~nm}) / \mathrm{Sm}\left(\mathrm{Co}_{0.9} \mathrm{Cu}_{0.1}\right)_{5}(50 \mathrm{~nm}) / \mathrm{Fe}_{2} \mathrm{Co}(10 \mathrm{~nm}) / \mathrm{Ru}(20 \mathrm{~nm})$ film (see Fig. 8h), the demagnetization process is continuous along the OOP direction. Along in-plane direction, a two-step behavior is observed on the hysteresis loop near zero fields.

Figure 9 compares the experimental coercivities along the easy axis direction as a function of $\mathrm{Fe}_{2} \mathrm{Co}$ thickness in $\mathrm{MgO} / \mathrm{Cr}(20 \mathrm{~nm}) / \mathrm{Sm}\left(\mathrm{Co}_{0.9} \mathrm{Cu}_{0.1}\right)_{5}(50 \mathrm{~nm}) / \mathrm{Fe}_{2} \mathrm{Co}(\mathrm{x} \mathrm{nm}) / \mathrm{Cr}(20$ 
nm) and $\mathrm{Al}_{2} \mathrm{O}_{3} / \mathrm{Ru}(20 \mathrm{~nm}) / \mathrm{Sm}\left(\mathrm{Co}_{0.9} \mathrm{Cu}_{0.1}\right)_{5}(50 \mathrm{~nm}) / \mathrm{Fe}_{2} \mathrm{Co}(\mathrm{x} \mathrm{nm}) / \mathrm{Ru}(20 \mathrm{~nm})$ films. Note that almost similar coercivities of $3.24 \mathrm{~T}$ and $3.56 \mathrm{~T}$ are achieved in Films 2 and 3. But the coercivity is only $0.59 \mathrm{~T}$ in the $\mathrm{MgO} / \mathrm{Cr}(20 \mathrm{~nm}) / \mathrm{Sm}\left(\mathrm{Co}_{0.9} \mathrm{Cu}_{0.1}\right)_{5}(50 \mathrm{~nm}) / \mathrm{Fe}_{2} \mathrm{Co}(10$ $\mathrm{nm}) / \mathrm{Cr}(20 \mathrm{~nm})$ film, much lower than $1.25 \mathrm{~T}$ achieved in the $\mathrm{Al}_{2} \mathrm{O}_{3} / \mathrm{Ru}(20$ $\mathrm{nm}) / \mathrm{Sm}\left(\mathrm{Co}_{0.9} \mathrm{Cu}_{0.1}\right)_{5}(50 \mathrm{~nm}) / \mathrm{Fe}_{2} \mathrm{Co}(10 \mathrm{~nm}) / \mathrm{Ru}(20 \mathrm{~nm})$ film. It means that the coercivity drops much faster in the case of c-axis IP geometry than that of c-axis OOP geometry in $\operatorname{Sm}\left(\mathrm{Co}_{0.9} \mathrm{Cu}_{0.1}\right)_{5}$ layer.

\section{Discussion}

The important finding in this work is the effect of the c-axis geometry on the temperature dependence of coercivity. Irrespective of the c-axis geometries in the IP and OOP directions, the coercivities of the films at room temperature are more or less the same. Nevertheless, the temperature dependence of the $\operatorname{Sm}\left(\mathrm{Co}_{0.9} \mathrm{Cu}_{0.1}\right)_{5}$ film or the absolute value of $\beta$ is larger for the OOP geometry. This can be explained from the large value of $N_{\text {eff }}=6.83$ for the OOP geometry in contrast to $N_{\text {eff }}=1.2$ for the IP geometry. This means that the large magnetostatic field is responsible for the large temperature degradation of permanent magnets. The coercivity degradation of Nd-Fe-B sintered magnets is also known to be larger than that expected from the temperature dependence of the anisotropy field, $H_{\mathrm{A}}$, suggesting the reduction of the stray field will improve the temperature dependence of the coercivity even for the $\mathrm{Nd}-\mathrm{Fe}-\mathrm{B}$ system.

To understand the physical mechanism, schematics of different c-axis geometries in exchange coupled bilayer films are plotted in Figure 10a and 10b. Exchange coupling energy $E_{e x}$ and magnetostatic coupling energy $E_{\text {static }}$ are dependent on the angle between hard-magnetic moment and soft-magnetic moment, which are expressed as:

$$
E_{e x}=-A_{e x} \mathbf{m}_{h} \cdot \mathbf{m}_{0,0}
$$




$$
E_{\text {static }}=\sum_{i=0}^{i=n} \sum_{i=-k}^{i=k} \frac{\mu_{0}}{4 \pi r^{3}}\left[\mathbf{m}_{h} \mathbf{m}_{i, j}-\frac{3}{r^{2}}\left(\mathbf{m}_{h} \cdot \mathbf{r}\right)\left(\mathbf{m}_{i, j} \cdot \mathbf{r}\right)\right]
$$

Exchange coupling is a short-range interaction because exchange stiffness $A_{e x}$ decays exponentially within several nanometers [30-33]. On the other hand, magnetostatic coupling is a long-range interaction due to the integration of every moment in both hard/soft-magnetic layers as seen from Fig. 10 and $E_{\text {static }}$ expression. Its long-range feature was experimentally confirmed in the Ta spacer of $\mathrm{Nd}_{2} \mathrm{Fe}_{14} \mathrm{~B} / \alpha-\mathrm{Fe}$ multilayer films [34]. For simplicity, the total coupling energy in different c-axis geometries between neighboring hard-magnetic moment $\boldsymbol{m}_{h}$ and soft-magnetic moment $\boldsymbol{m}_{0,0}$ are compared in Fig. 10c. Obviously, in both geometries, $E_{e x}$ is negative and causes the parallel alignment of hard/soft-magnetic moments. On the other hand, in c-axis OOP geometry, $E_{\text {static }}$ is negative compared with positive one in the c-axis IP geometry, leading to energetically preferred and stronger coupling in the c-axis OOP geometry. Therefore, higher coercivities are achieved in the bilayer films with c-axis OOP in the $\operatorname{Sm}\left(\mathrm{Co}_{0.9} \mathrm{Cu}_{0.1}\right)_{5}$ layer than that with the c-axis IP geometry. In the OOP exchange coupling geometry, the observed two-step behavior in Fig.8h can also be explained by the magnetostatic coupling. Along in-plane direction of OOP exchange coupling geometry, forced by the external field, the moments in hard-magnetic phase are tilted from easy axis and close to in-plane direction. When the external field is swept to zero fields, confined by the out-of-plane easy axis, the moments in hard-magnetic phase tend to be back to easy axis. Meanwhile, the soft-magnetic moments also tend to be reversed due to the repulsive interaction caused by the magnetostatic coupling when the hysteresis loops are measured along in-plane direction. Therefore, non-uniform magnetization reversal process happens leading to the two-step behavior observed in IP hysteresis loops as shown in Fig. $8 \mathrm{~h}$.

In order to confirm the experimental results, finite element micromagnetic simulation 
was employed to study coercivity as a function of $\mathrm{Fe}_{2} \mathrm{Co}$ thickness in $\mathrm{Sm}\left(\mathrm{Co}_{0.9} \mathrm{Cu}_{0.1}\right)_{5}(50$ $\mathrm{nm}) / \mathrm{Fe}_{2} \mathrm{Co}(\mathrm{x} \mathrm{nm})$ exchange coupled bilayer films with c-axis IP and OOP geometries in the $\mathrm{Sm}\left(\mathrm{Co}_{0.9} \mathrm{Cu}_{0.1}\right)_{5}$ layers. Figure 11 (a) and (b) shows the modeled thin films with c-axis IP and OOP geometries for $\mathrm{Sm}\left(\mathrm{Co}_{0.9} \mathrm{Cu}_{0.1}\right)_{5}$ layers. $\mathrm{Fe}_{2} \mathrm{Co}$ layer with different thicknesses of 0 to 10 $\mathrm{nm}$ is located at the top surface of $\operatorname{Sm}\left(\mathrm{Co}_{0.9} \mathrm{Cu}_{0.1}\right)_{5}$ film. Due to formation of stacking faults at basal planes of $\mathrm{SmCo}_{5}$ phase (Figure 4), variants of $\mathrm{Sm}$-Co phases including $\mathrm{SmCo}_{3}, \mathrm{SmCo}_{5}$, $\mathrm{Sm}_{2} \mathrm{Co}_{7}$ phases with thickness of $\sim 2-5 \mathrm{~nm}$ forms in each $\mathrm{SmCo}_{5}$ grain [35]. Hence, we considered stacks of $\mathrm{Sm}-\mathrm{Co}$ phases in each $\mathrm{SmCo}_{5}$ grains as shown schematically with different colors in Fig. 11 (a) and (b). Table 3 summarizes the magnetic properties of Sm-Co phases assumed in the simulation $[7,9,10,34]$. Note that since there is no systematic report on the influence of trace addition of $\mathrm{Cu}$ to the magnetic properties of $\mathrm{SmCo}_{3}$ and $\mathrm{Sm}_{2} \mathrm{Co}_{7}$ phases, intrinsic magnetic properties of these phases without $\mathrm{Cu}$ were used in the simulation [36]. The simulated coercivity dependence of $\mathrm{Fe}_{2} \mathrm{Co}$ thickness is plotted in Fig. 11c. It is found that with increasing thickness of $\mathrm{Fe}_{2} \mathrm{Co}$ layer, coercivity degrades for both films. However, coercivity degradation is more pronounced for c-axis IP geometry, which is in agreement with the tendency as observed in Fig.9.

Figure 12 (a) shows magnetization curves for the $\mathrm{Sm}$-Co models for $\operatorname{Sm}\left(\mathrm{Co}_{0.9} \mathrm{Cu}_{0.1}\right)_{5}$ single layer film with c-axis IP and OOP. Magnetization configuration at point (i) to (iii) marked in the magnetization curves are shown in Fig. 12 (b) and (c) for the c-axis IP and OOP geometries, respectively. Magnetization reversal starts on the surface perpendicular to c-axis for the IP and OOP geometries. In the case of c-axis IP, domain wall get pinned at the interface of variants of Sm-Co phases with different magnetocrystalline anisotropy induced by the stacking faults as reported by Akdogan et al. [34]. However, in the case of c-axis OOP (Fig. 12 (c)), pinning by the interface of Sm-Co variants are not as clear as observed for the 
c-axis IP sample (Fig. 12 (b)). This is due to a larger demagnetization field for the c-axis OOP model which has positive contribution to the magnetization reversal via domain wall propagation parallel to the c-axis. Figure 12 (d) compares magnetization curves of the $\mathrm{Sm}\left(\mathrm{Co}_{0.9} \mathrm{Cu}_{0.1}\right)_{5} / \mathrm{Fe}_{2} \mathrm{Co}$ bilayer films with c-axis IP and OOP with $t_{\mathrm{Fe} 2 \mathrm{Co}}=3 \mathrm{~nm}$. Note that step like demagnetization curves that differs from experimentally measured magnetization curves are due to the limited number of grains in the micromagnetic simulation. To show how the magnetization reversal takes place for the IP and OOP geometries with a $3 \mathrm{~nm}$ thick $\mathrm{Fe}_{2} \mathrm{Co}$ layer, magnetization configuration for points (i) to (iii) marked in the magnetization curves are shown in Fig. 12 (e) and (f). In both models, magnetization reversals start from the $\mathrm{Fe}_{2} \mathrm{Co}$ layer. However, magnetic domain walls get pinned strongly at the interface between the $\mathrm{Fe}_{2} \mathrm{Co}$ layer and the $\mathrm{Sm}\left(\mathrm{Co}_{0.9} \mathrm{Cu}_{0.1}\right)_{5}$ phase in the c-axis OOP sample since the direction of domain wall motion is perpendicular to the stacking faults. On the other hand, in the case of c-axis IP, domain walls move parallel to stacking faults in the $\operatorname{Sm}\left(\mathrm{Co}_{0.9} \mathrm{Cu}_{0.1}\right)_{5}$ phase with minimum pinning area, resulting in a weaker pinning force. Hence, besides the stronger coupling between soft/hard-magnetic layers in the c-axis OOP geometry, micromagnetic simulations suggest that a stronger pinning force against domain wall motion from $\mathrm{Fe}_{2} \mathrm{Co}$ layer into the $\mathrm{Sm}\left(\mathrm{Co}_{0.9} \mathrm{Cu}_{0.1}\right)_{5}$ layer is another reason for the smaller degradation of coercivity with increasing $\mathrm{Fe}_{2} \mathrm{Co}$ thickness in the c-axis OOP geometry.

\section{Conclusion}

Different morphologies and c-axis geometries can be realized in $\operatorname{Sm}\left(\mathrm{Co}_{0.9} \mathrm{Cu}_{0.1}\right)_{5}$ films and their relationships with coercivity and its thermal stability, have been clarified. Our work supports that the coercivity is enhanced by grain isolation in $\operatorname{Sm}\left(\mathrm{Co}_{0.9} \mathrm{Cu}_{0.1}\right)_{5}$ thin film with c-axis IP geometry. Meanwhile, thermal stability of coercivity is found to be improved if 
c-axis IP geometry is realized in the $\operatorname{Sm}\left(\mathrm{Co}_{0.9} \mathrm{Cu}_{0.1}\right)_{5}$ film due to reduced magnetostatic field. In $\mathrm{Sm}\left(\mathrm{Co}_{0.9} \mathrm{Cu}_{0.1}\right)_{5} / \mathrm{Fe}_{2} \mathrm{Co}$ bilayer films, the coercivity decreases faster with increasing thickness of $\mathrm{Fe}_{2} \mathrm{Co}$ layer if the c-axis of $\mathrm{Sm}\left(\mathrm{Co}_{0.9} \mathrm{Cu}_{0.1}\right)_{5}$ is IP, which is explained by an unfavorable magnetostatic coupling between hard/soft-magnetic layers consistent with micromagnetic simulations. This work has clarified the relationships among grain morphology, c-axis geometry with coercivity and its temperature dependence, which are useful clues for further development of high-performance permanent magnets.

\section{Acknowledgment}

This work was partly supported by the Elements Strategy Initiative Project under the auspice of MEXT and JST, CREST. 


\section{Reference:}

[1] K. Hono and H. Sepehri-Amin, Strategy for high-coercivity Nd-Fe-B magnets, Scripta Mater. 67 (2012) 530-535.

[2] H. Sepehri-Amin, , T. Ohkubo, S. Nagashima, M. Yano, T. Shoji, A. Kato, T. Schrefl, K. Hono, High-coercivity ultrafine-grained anisotropic $\mathrm{Nd}-\mathrm{Fe}-\mathrm{B}$ magnets processed by hot deformation and the $\mathrm{Nd}-\mathrm{Cu}$ grain boundary diffusion process, Acta Mater. 61 (2013) $6622-6634$.

[3] T. Akiya, J. Liu, H. Sepehri-Amin, T. Ohkubo, K. Hioki, A. Hattori and K. Hono, Low temperature diffusion process using rare earth-Cu eutectic alloys for hot-deformed Nd-Fe-B bulk magnets, J. Appl. Phys. 115 (2014) 17A766-1-3.

[4] T. Akiya, J. Liu, H. Sepehri-Amin, T. Ohkubo, K. Hioki, A. Hattori, K. Hono, High-coercivity hot-deformed $\mathrm{Nd}-\mathrm{Fe}-\mathrm{B}$ permanent magnets processed by $\mathrm{Nd}-\mathrm{Cu}$ eutectic diffusion under expansion constraint, Scripta Mater. 81 (2014) 48-51.

[5] H. Sepehri-Amin, Lihua Liu, T. Ohkubo, M. Yano, T. Shoji, A. Kato, T. Schrefl, K. Hono, Microstructure and temperature dependent of coercivity of hot-deformed $\mathrm{Nd}-\mathrm{Fe}-\mathrm{B}$ magnets diffusion processed with $\mathrm{Pr}-\mathrm{Cu}$ alloy, Acta Mater. 99 (2015) 297-306.

[6] J. Liu, H. Sepehri-Amin, T. Ohkubo, K. Hioki, A. Hattori, T. Schrefld, K. Hono, Effect of $\mathrm{Nd}$ content on the microstructure and coercivity of hot-deformed $\mathrm{Nd}-\mathrm{Fe}-\mathrm{B}$ permanent magnets, Acta Mater. 61 (2013) 5387-5399

[7] W. B. Cui, Y. K. Takahashi, K. Hono, Microstructure optimization to achieve high coercivity in anisotropic Nd-Fe-B thin films, Acta Mater. 59 (2011) 7768-7775

[8] J. Liu, H. Sepehri-Amin, T. Ohkubo, K. Hioki, A. Hattori, T. Schrefl, K. Hono, Grain size dependence of coercivity of hot-deformed Nd-Fe-B anisotropic magnets, Acta Mater. 82 (2015) 336-343. 
[9] E. Lectard, C. H. Allibert and R. Ballou, Saturation magnetization and anisotropy fields in the $\operatorname{Sm}\left(\mathrm{Co}_{1-\mathrm{x}} \mathrm{Cu}_{\mathrm{x}}\right)_{5}$ phases, J. Appl. Phys. 75 (1994) 6277-6279.

[10]K. Kumar, RETM 5 and $\mathrm{RE}_{2} \mathrm{TM}_{17}$ permanent magnets development, J. Appl. Phys. 63 (1988) R13-R57.

[11]E. E. Fullerton, C. H. Sowers, J. P. Pearson, S. D. Bader, X. Z. Wu, D. Lederman, A general approach to the epitaxial growth of rare-earth-transition-metal films, App. Phys. Lett. 69 (1996) 2438-2440

[12]A. Singh, V. Neu, S. Faehler, K. Nenkov, L. Shultz and B. Holzapfel, Mechanism of coercivity in epitaxial $\mathrm{SmCo}_{5}$ thin films, Phys. Rev. B 77 (2008) 104443-1-6.

[13]M. Seifrt, V. Neu and L. Shultz, Epitaxial $\mathrm{SmCo}_{5}$ thin films with perpendicular anisotropy, App. Phys. Lett. 94 (2009) 022501-1-3.

[14]E. F. Kneller and R. Hawig, The Exchange-Spring Magnet: A New Material Principle for Permanent Magnets, IEEE Trans.Mag. 27 (1991) 3588-3600.

[15]R. Skomski and J M D Coey, Giant energy product in nanostructured two-phase magnets, Phys Rev. B 48 (1993) 15812-15816.

[16]R. Skomski, P. Manchanda, P. Kumar, B. balamurugan, A. Kashyap and D. J. Sellmyer, Predicting the Future of Permanent-Magnet Materials, IEEE Trans. Magn. 49 (2013) $3215-3220$.

[17]R. Skomski, Nanomagnetics, J. Phys.:Condens Matter 15 (2003) R841-R896.

[18]R. Skomski, Micromagnetic localization, J. Appl. Phys. 83 (1998) 6503-6505.

[19] J. S. Jiang and S. D. Bader, Rational design of the exchange-spring permanent magnet, J. Phys.: Condens. Matter 26 (2014) 064214-1-9.

[20] S. Sawatzki, R. Heller, C. Mickel, M. Seifert, L. Schultz and V. Neu, Largely enhanced energy density in epitaxial $\mathrm{SmCo}_{5} / \mathrm{Fe} / \mathrm{SmCo}_{5}$ exchange spring trilayers, J. Appl. Phys. 109 
(2011) 123922-1-7.

[21] V. Neu, S. Sawatzki, M. Kopte, C. Mickel and L. Schultz, Fully Epitaxial, Exchange Coupled $\mathrm{SmCo}_{5} / \mathrm{Fe}$ Multilayers With Energy Densities above $400 \mathrm{~kJ} / \mathrm{m}^{3}$, IEEE. Trans. Magn. 48 (2012) 3599-3602.

[22]J. Zhang, Y. K. Takahashi, R. Gopalan and K. Hono, $\mathrm{Sm}(\mathrm{Co}, \mathrm{Cu})_{5} / \mathrm{Fe}$ exchange spring multilayer films with high energy product, Appl. Phys. Lett. 86, 122509 (2005).

[23]J. Zhang, Y.K. Takahashi, R. Gopalan, K. Hono, Microstructures and coercivities of $\mathrm{SmCo}_{x}$ and $\mathrm{Sm}(\mathrm{Co}, \mathrm{Cu})_{5}$ films prepared by magnetron sputtering, J. Mag. Mag. Mater. 310 , 1 (2007).

[24]E. Lectard, C. H. Allibert, and R. Balllou, Saturation magnetization and anisotropy fields in the $\mathrm{Sm}(\mathrm{Co} 1-\mathrm{xCux}) 5$ phases, J. Appl. Phys. 75, 15 (1994).

[25]T. Schrefl and J. Fidler, Micromagnetic simulation of magnetizability of nanocomposite Nd-Fe-B magnets, J. Appl. Phys. 83 (1998) 6262-6264.

[26]X. Q. Liu, H. B. Zhao,Y. Kubota, J. P. Wang, Polycrystalline $\operatorname{Sm}(\mathrm{Co}, \mathrm{Cu})_{5}$ films with

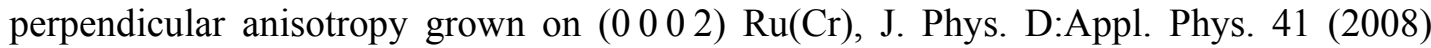
$232002-1-5$.

[27]L. Zhang, Y. K. Takahashi, K. Hono, B. C. Stipe, J. Y. Juang and M. Grobis, $L 1_{0}$-ordered FePtAg-C granular thin film for thermally assisted magnetic recording media (invited), J. Appl. Phys. 109 (2011) 07B703-1-3.

[28] W. F. Brown, Virtues and Weaknesses of the Domain Concept, Rev. Mod. Phys. 17 (1945) $15-19$.

[29]H. Kronmuller, K. D. Durst and G. Martinek, Angular dependence of the coercive field in sintered $\mathrm{Fe}_{77} \mathrm{Nd}_{15} \mathrm{~B}_{8}$ magnets, J. Magn. Magn. Mater. 69 (1987) 149-157.

[30] S. S. P. Parkin, N. More and K. P. Roche, Oscillations in exchange coupling and 
magnetoresistance in metallic superlattice structures: $\mathrm{Co} / \mathrm{Ru}, \mathrm{Co} / \mathrm{Cr}$, and $\mathrm{Fe} / \mathrm{Cr}$, Phys. $\mathrm{Rev}$ Lett. 64 (1990) 2304-2307.

[31]P. Bruno, Theory of interlayer magnetic coupling, Phys. Rev. B 52 (1995) 411-439.

[32]F. Garcia, J. Sort, B. Rodmacq, S. Auffret and B. Dieny, Large anomalous enhancement of perpendicular exchange bias by introduction of a nonmagnetic spacer between the ferromagnetic and antiferromagnetic layers, Appl. Phys. Lett. 83 (2003) 3537-3539.

[33]L. Thomas, A. J. Kellock and S. S. P. Parkin, On the exchange biasing through a nonmagnetic spacer layer, J. Appl. Phys. 87 (2000) 5061-5063.

[34]O. Akdogan, H. Sepehri-Amin, N. M. Dempsey, T. Ohkubo, K. Hono, O. Gutfleisch, T. Schrefl and D. Givord, Preparation, Characterization, and Modeling of Ultrahigh Coercivity Sm-Co Thin Films, Adv. Electron. Mater. 1 (2015) 1500009-1-8.

[35] W. B. Cui, H. Sepehri-Amin, Y. K. Takahashi and K. Hono, Hard magnetic properties of spacer-layer-tuned NdFeB/Ta/Fe nanocomposite films, Acta Mater. 84 (2015) 405-412.

[36] W. B. Cui, Y. K. Takahashi and K. Hono, $\mathrm{Nd}_{2} \mathrm{Fe}_{14} \mathrm{~B} / \mathrm{FeCo}$ anisotropic nanocomposite films with a large maximum energy product, Adv. Mater. 24 (2012) 6530-6535. 


\section{Figure captions}

Fig. 1 XRD diffraction patterns of $\mathrm{MgO} / \mathrm{Cr}(20 \mathrm{~nm}) / \mathrm{Sm}\left(\mathrm{Co}_{0.9} \mathrm{Cu}_{0.1}\right)_{5}(50 \mathrm{~nm}) / \mathrm{Cr}(20 \mathrm{~nm})$ film

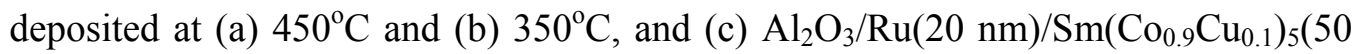
$\mathrm{nm}) / \mathrm{Ru}(20 \mathrm{~nm})$ film deposited at $350^{\circ} \mathrm{C}$

Fig. 2 Hystersis loops of $\mathrm{MgO} / \mathrm{Cr}(20 \mathrm{~nm}) / \mathrm{Sm}\left(\mathrm{Co}_{0.9} \mathrm{Cu}_{0.1}\right)_{5}(50 \mathrm{~nm}) / \mathrm{Cr}(20 \mathrm{~nm})$ film deposited at (a) $450^{\circ} \mathrm{C}$ (Film 1) and (b) $350^{\circ} \mathrm{C}$ (Film 2), and (c) $\mathrm{Al}_{2} \mathrm{O}_{3} / \mathrm{Ru}(20$ $\mathrm{nm}) / \mathrm{Sm}\left(\mathrm{Co}_{0.9} \mathrm{Cu}_{0.1}\right)_{5}(50 \mathrm{~nm}) / \mathrm{Ru}(20 \mathrm{~nm})$ film deposited at $350^{\circ} \mathrm{C}$ (Film 3) along out-of-plane (OOP) and in-plane (IP) directions.

Fig. 3 The cross-sectional bright-field TEM image of $\mathrm{MgO} / \mathrm{Cr}(20 \mathrm{~nm}) / \mathrm{Sm}\left(\mathrm{Co}_{0.9} \mathrm{Cu}_{0.1}\right)_{5}(50$ $\mathrm{nm}) / \mathrm{Cr}(20 \mathrm{~nm})$ film deposited at $450^{\circ} \mathrm{C}$ (a), and $350^{\circ} \mathrm{C}$ along [ $\left[\begin{array}{lll}0 & 0 & 1\end{array}\right]$ zone axis (b) and [ $\left.\begin{array}{lll}1 & 1 & 0\end{array}\right]$ zone axis (c) of MgO substrate; (d) cross-sectional bright-field TEM image of $\mathrm{Al}_{2} \mathrm{O}_{3} / \mathrm{Ru}(20 \mathrm{~nm}) / \mathrm{Sm}\left(\mathrm{Co}_{0.9} \mathrm{Cu}_{0.1}\right)_{5}(50 \mathrm{~nm}) / \mathrm{Ru}(20 \mathrm{~nm})$ film deposited at $350^{\circ} \mathrm{C}$. The c-axis direction is marked in black and the stacking faults are marked in yellow. (e) and (f) are the nano beam diffraction patterns of $\mathrm{MgO}$ substrate and $\operatorname{Sm}\left(\mathrm{Co}_{0.9} \mathrm{Cu}_{0.1}\right)_{5}$ layer in Fig. 3b. (g) and (h) are the patterns from $\mathrm{MgO}$ substrate and $\mathrm{Sm}\left(\mathrm{Co}_{0.9} \mathrm{Cu}_{0.1}\right)_{5}$ layer in Fig. 3c.

Fig. 4 HAADF-STEM images of $\operatorname{Sm}\left(\mathrm{Co}_{0.9} \mathrm{Cu}_{0.1}\right)_{5}$ phase along $\left[\begin{array}{llll}0 & 0 & 0 & 1\end{array}\right]$ zone axis (a) and $[1$ $\left.\begin{array}{lll}0 & \overline{1} & 0\end{array}\right]$ zone axis (b). (c) Schematic formation mechanism of stacking faults within $\mathrm{SmCo}_{5}\left(\begin{array}{llll}0 & 0 & 0 & 1\end{array}\right)$ plane. The inset figure in Fig. 4a compares the atomic occupations in the top part and down part of Fig. 4a. The inset figure in Fig. $4 \mathrm{~b}$ shows the atomic terrace in the region of stacking faults.

Fig. 5 Coercivity temperature dependence of $\mathrm{MgO} / \mathrm{Cr}(20 \mathrm{~nm}) / \mathrm{Sm}\left(\mathrm{Co}_{0.9} \mathrm{Cu}_{0.1}\right)_{5}(50$ $\mathrm{nm}) / \mathrm{Cr}(20 \mathrm{~nm})$ film deposited at $450^{\circ} \mathrm{C}$ (Film 1, red square) and $350^{\circ} \mathrm{C}$ (Film 2, blue circle), and $\mathrm{Al}_{2} \mathrm{O}_{3} / \mathrm{Ru}(20 \mathrm{~nm}) / \mathrm{Sm}\left(\mathrm{Co}_{0.9} \mathrm{Cu}_{0.1}\right)_{5}(50 \mathrm{~nm}) / \mathrm{Ru}(20 \mathrm{~nm})$ film (Film 3, dark 
diamond).

Fig. 6 Schematics of morphology changes and magnetostatic distributions in $\mathrm{MgO} / \mathrm{Cr}(20$ $\mathrm{nm}) / \mathrm{Sm}\left(\mathrm{Co}_{0.9} \mathrm{Cu}_{0.1}\right)_{5}(50 \mathrm{~nm}) / \mathrm{Cr}(20 \mathrm{~nm})$ film deposited at $450^{\circ} \mathrm{C}($ Film 1$)$ and $350^{\circ} \mathrm{C}$ (Film 2), and $\mathrm{Al}_{2} \mathrm{O}_{3} / \mathrm{Ru}(20 \mathrm{~nm}) / \mathrm{Sm}\left(\mathrm{Co}_{0.9} \mathrm{Cu}_{0.1}\right)_{5}(50 \mathrm{~nm}) / \mathrm{Ru}(20 \mathrm{~nm})$ film deposited at $350^{\circ} \mathrm{C}$ (Film 3). Coercivity $\mathrm{H}_{\mathrm{c}}$, coercivity temperature coefficiency $\beta$ and micromagnetic parameters $\alpha$ and $N_{\text {eff }}$ are shown and compared. The arrows show the magnetization direction.

Fig. 7 XRD diffraction patterns of (a) $\mathrm{MgO} / \mathrm{Cr}(20 \mathrm{~nm}) / \mathrm{Sm}\left(\mathrm{Co}_{0.9} \mathrm{Cu}_{0.1}\right)_{5}(50 \mathrm{~nm}) / \mathrm{Fe}_{2} \mathrm{Co}(\mathrm{x}$ $\mathrm{nm}) / \mathrm{Cr}(20 \mathrm{~nm})$ films with c-axis in-plane (IP) geometry and (b) $\mathrm{Al}_{2} \mathrm{O}_{3} / \mathrm{Ru}(20$ $\mathrm{nm}) / \mathrm{Sm}\left(\mathrm{Co}_{0.9} \mathrm{Cu}_{0.1}\right)_{5}(50 \mathrm{~nm}) / \mathrm{Fe}_{2} \mathrm{Co}(\mathrm{x} \mathrm{nm}) / \mathrm{Ru}(20 \mathrm{~nm})$ films with c-axis out-of-plane (OOP) geometry ( $\mathrm{x}=0 \mathrm{~nm}$ (single-layer film), $3 \mathrm{~nm}, 5 \mathrm{~nm}, 8 \mathrm{~nm}$ and $10 \mathrm{~nm})$

Fig. 8 Hysteresis loops of $\mathrm{MgO} / \mathrm{Cr}(20 \mathrm{~nm}) / \mathrm{Sm}\left(\mathrm{Co}_{0.9} \mathrm{Cu}_{0.1}\right)_{5}(50 \mathrm{~nm}) / \mathrm{Fe}_{2} \mathrm{Co}(\mathrm{x} \mathrm{nm}) / \mathrm{Cr}(20 \mathrm{~nm})$ films with c-axis in-plane (IP) geometry(x = $3 \mathrm{~nm}(\mathrm{a}), 5 \mathrm{~nm}(\mathrm{~b}), 8 \mathrm{~nm}$ (c) and $10 \mathrm{~nm}$ (d)) and $\mathrm{Al}_{2} \mathrm{O}_{3} / \mathrm{Ru}(20 \mathrm{~nm}) / \mathrm{Sm}\left(\mathrm{Co}_{0.9} \mathrm{Cu}_{0.1}\right)_{5}(50 \mathrm{~nm}) / \mathrm{Fe}_{2} \mathrm{Co}(\mathrm{x} \mathrm{nm}) / \mathrm{Ru}(20 \mathrm{~nm})$ films with c-axis out-of-plane (OOP) geometry $(\mathrm{x}=3 \mathrm{~nm}(\mathrm{e}), 5 \mathrm{~nm}(\mathrm{f}), 8 \mathrm{~nm}(\mathrm{~g})$ and 10 $\mathrm{nm}(\mathrm{h}))$

Fig. 9 The coercivities obtained by experiments as a function of $\mathrm{Fe}_{2} \mathrm{Co}$ layer thickness in $\mathrm{MgO} / \mathrm{Cr}(20 \mathrm{~nm}) / \mathrm{Sm}\left(\mathrm{Co}_{0.9} \mathrm{Cu}_{0.1}\right)_{5}(50 \mathrm{~nm}) / \mathrm{Fe}_{2} \mathrm{Co}(\mathrm{x} \mathrm{nm}) / \mathrm{Cr}(20 \mathrm{~nm})$ films with c-axis in-plane (IP) geometry and $\mathrm{Al}_{2} \mathrm{O}_{3} / \mathrm{Ru}(20 \mathrm{~nm}) / \mathrm{Sm}\left(\mathrm{Co}_{0.9} \mathrm{Cu}_{0.1}\right)_{5}(50 \mathrm{~nm}) / \mathrm{Fe}_{2} \mathrm{Co}(\mathrm{x}$ $\mathrm{nm}) / \mathrm{Ru}(20 \mathrm{~nm})$ films with c-axis out-of-plane (OOP) geometry.

Fig. 10 Schematics of c-axis out-of-plane (OOP) (a) and in-plane (IP) (b) exchange coupling (EC) geometries in exchange-coupled bilayer films. (c) Comparisons of exchange coupling energy $\left(E_{e x}\right)$ and magnetostatic energy $\left(E_{\text {static }}\right)$ between moment $m_{k}$ in hard-magnetic layer and $m_{0,0}$ in soft-magnetic layer as shown in Fig. 10a and 
Fig.10b.

Fig. 11 Simulated $\mathrm{Sm}\left(\mathrm{Co}_{0.9} \mathrm{Cu}_{0.1}\right)_{5}(50 \mathrm{~nm}) / \mathrm{Fe}_{2} \mathrm{Co}(\mathrm{x} \mathrm{nm})$ model film structure with c-axis in-plane (a) and out-of-plane (b) geometry in $\mathrm{Sm}\left(\mathrm{Co}_{0.9} \mathrm{Cu}_{0.1}\right)_{5}$ layer. $\mathrm{Fe}_{2} \mathrm{Co}$ layer with different thicknesses of 0 to $10 \mathrm{~nm}$ is located at the top of Sm-Co layer. $2 \mathrm{~nm}$ thickness of soft-magnetic grain boundaries were introduced into the model with same saturation magnetization $\left(\mu_{0} M_{s}\right)$ and exchange stiffness as hard-magnetic phase but zero magnetocrystalline anisotropy $\left(\mu_{0} H_{A}\right)$. The Each model with a size of $102 \times 102 \times 50 \mathrm{~nm}^{3}$ was comprised of four $\mathrm{SmCo}_{5}$ grains with size of $50 \times 50 \times 50 \mathrm{~nm}^{3}$. (c) Comparisons of the coercivities obtained micromagnetic simulations as a function of $\mathrm{Fe}_{2} \mathrm{Co}$ layer thickness for the models with c-axis in-plane (IP) geometry and out-of-plane (OOP) geometry.

Fig. 12 Simulated magnetization curves of IP and OOP geometry with (a) $t_{\mathrm{Fe} 2 \mathrm{Co}}=0 \mathrm{~nm}$ and (d) $t_{\mathrm{Fe} 2 \mathrm{Co}}=3 \mathrm{~nm}$. Magnetic configurations at point i, ii and iii in Fig.12a are displayed in (b) and (c) with $t_{\mathrm{Fe} 2 \mathrm{Co}}=0 \mathrm{~nm}$ and different c-axis geometry. Similarly, Fig.12 (e) and (f) shows the magnetic configurations at point i, ii and iii in Fig.12d with $t_{\mathrm{Fe} 2 \mathrm{Co}}=$ $3 \mathrm{~nm}$ and different c-axis geometry. 
Table 3 Magnetic properties of Sm-Co phases used in the micromagnetic simulation $[7,9,10,31]$.

\begin{tabular}{|c|c|c|c|}
\hline & $\begin{array}{c}\mu_{0} \mathrm{M}_{\mathrm{s}} \\
(\mathrm{T})\end{array}$ & $\begin{array}{c}\mathrm{K}_{\mathrm{u}} \\
\left(\mathrm{MJ} / \mathrm{m}^{3}\right)\end{array}$ & $\begin{array}{c}\mathrm{A} \\
(\mathrm{pJ} / \mathrm{m})\end{array}$ \\
\hline $\mathrm{Sm}\left(\mathrm{Co}_{0.9} \mathrm{Cu}_{0.1}\right)_{5}$ & 1.0 & 17 & 8.6 \\
\hline $\mathrm{SmCo}_{3}$ & 0.4 & 0 & 4.3 \\
\hline $\mathrm{Sm}_{2} \mathrm{Co}_{7}$ & 0.8 & 6 & 8.6 \\
\hline $\mathrm{Fe}_{2} \mathrm{Co}$ & 2.45 & 0.0 & 22 \\
\hline
\end{tabular}




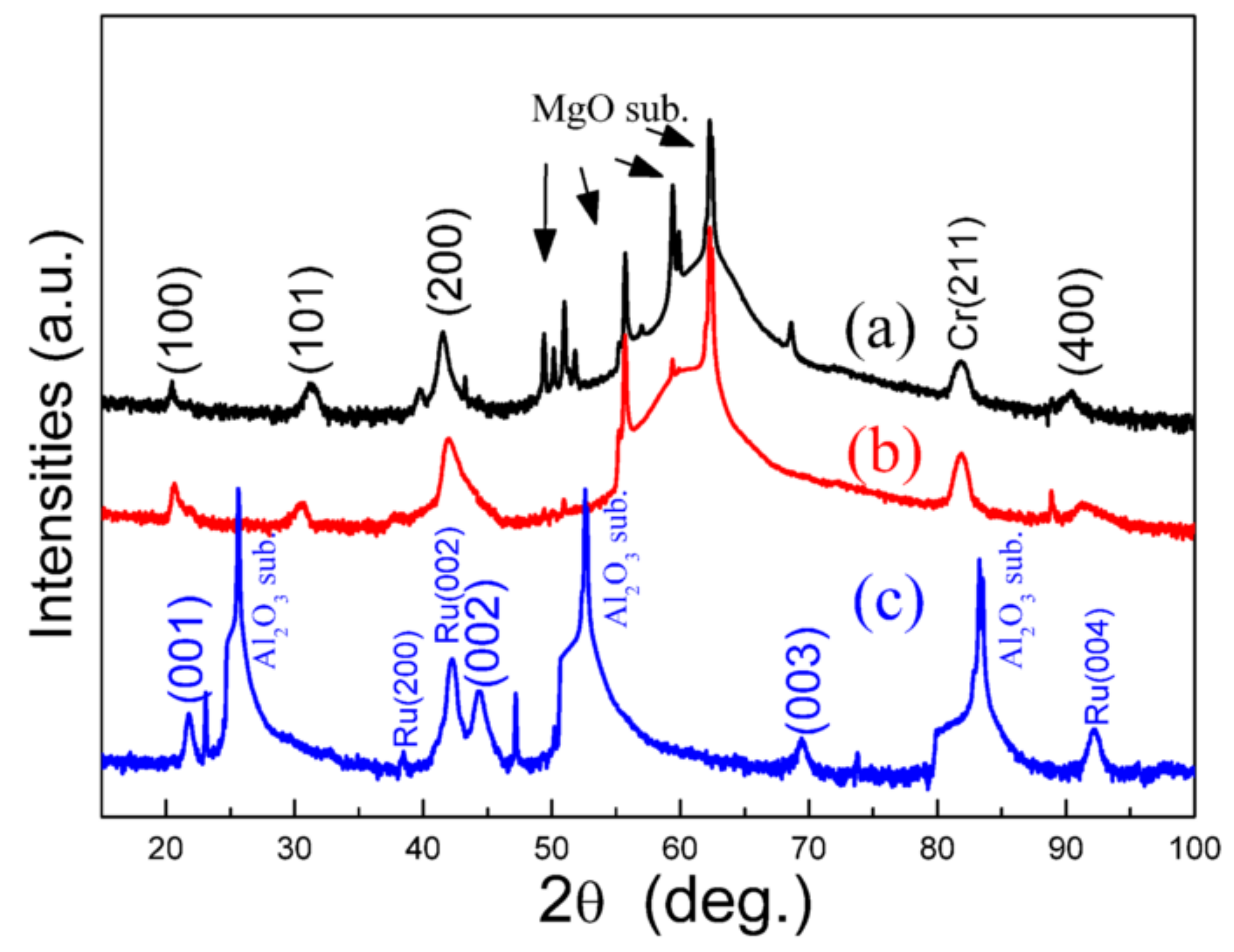



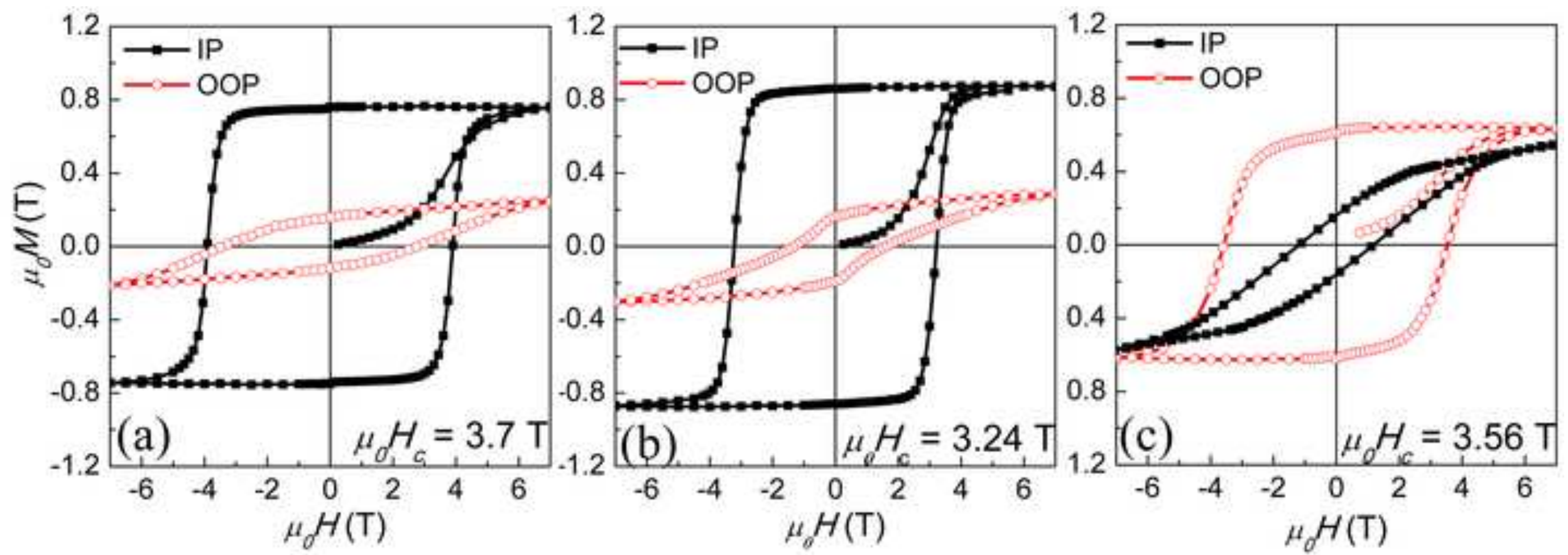

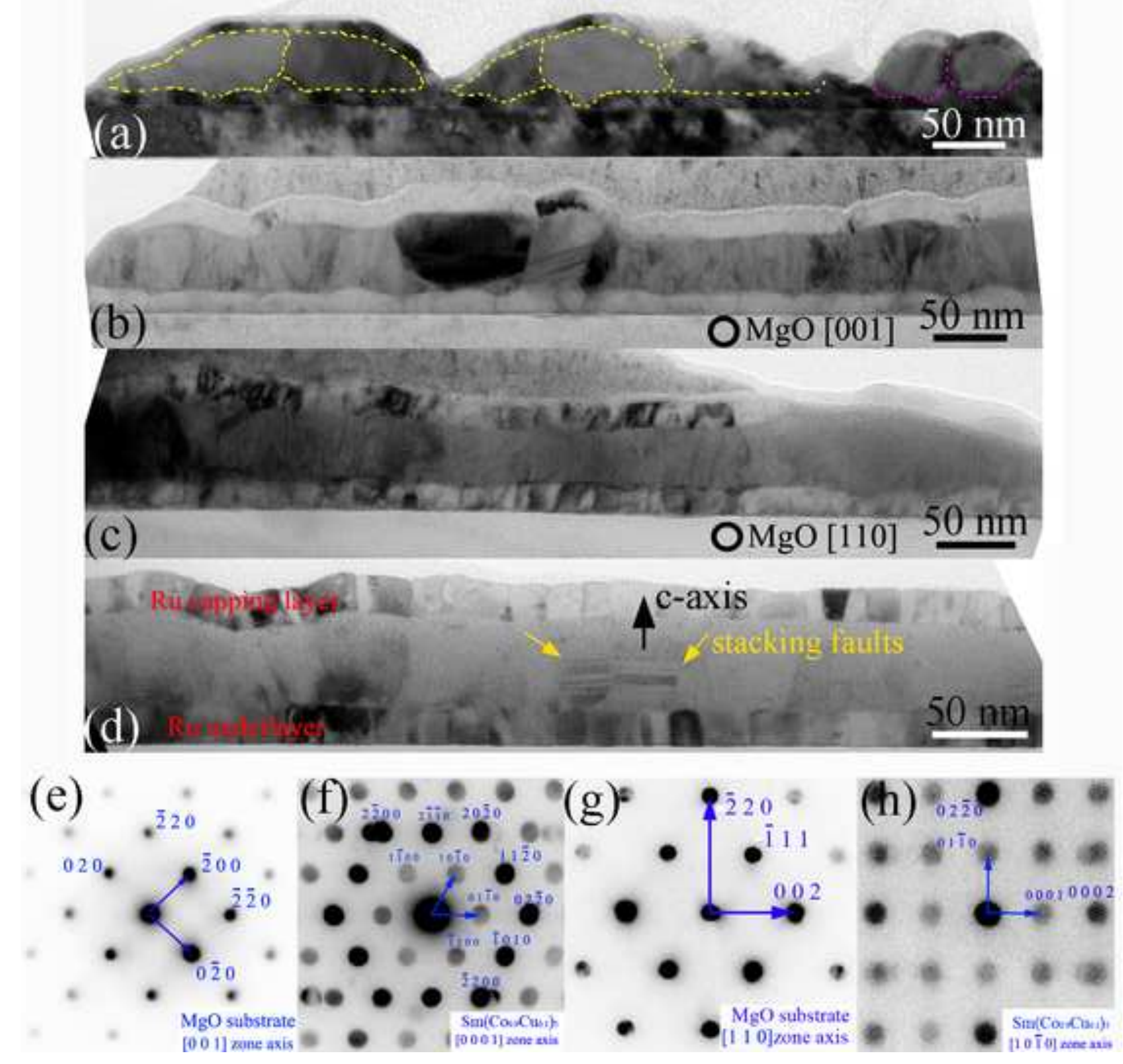

$$
\mathrm{OMgO}[110] \underline{50 \mathrm{~nm}}
$$




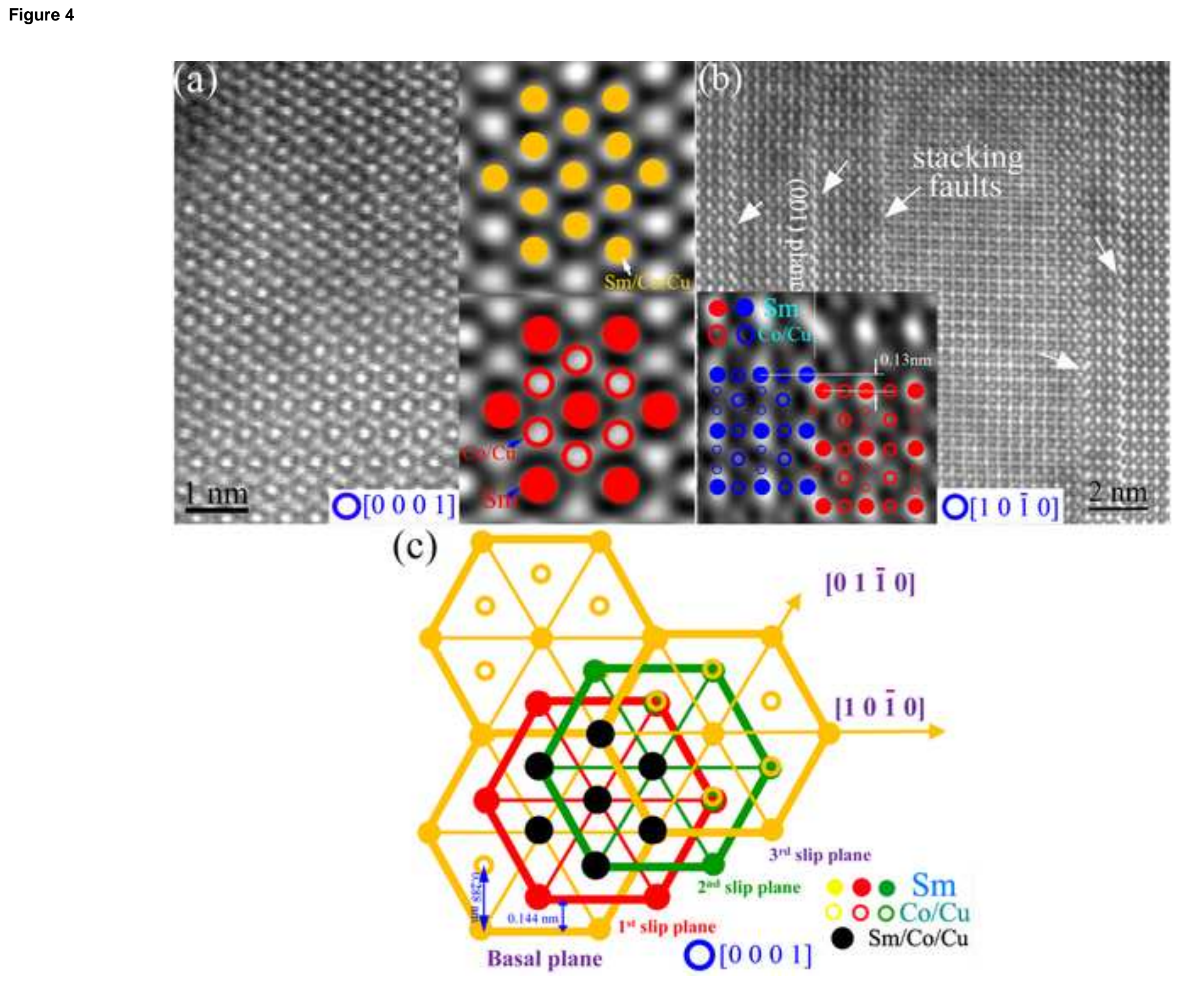

(c)

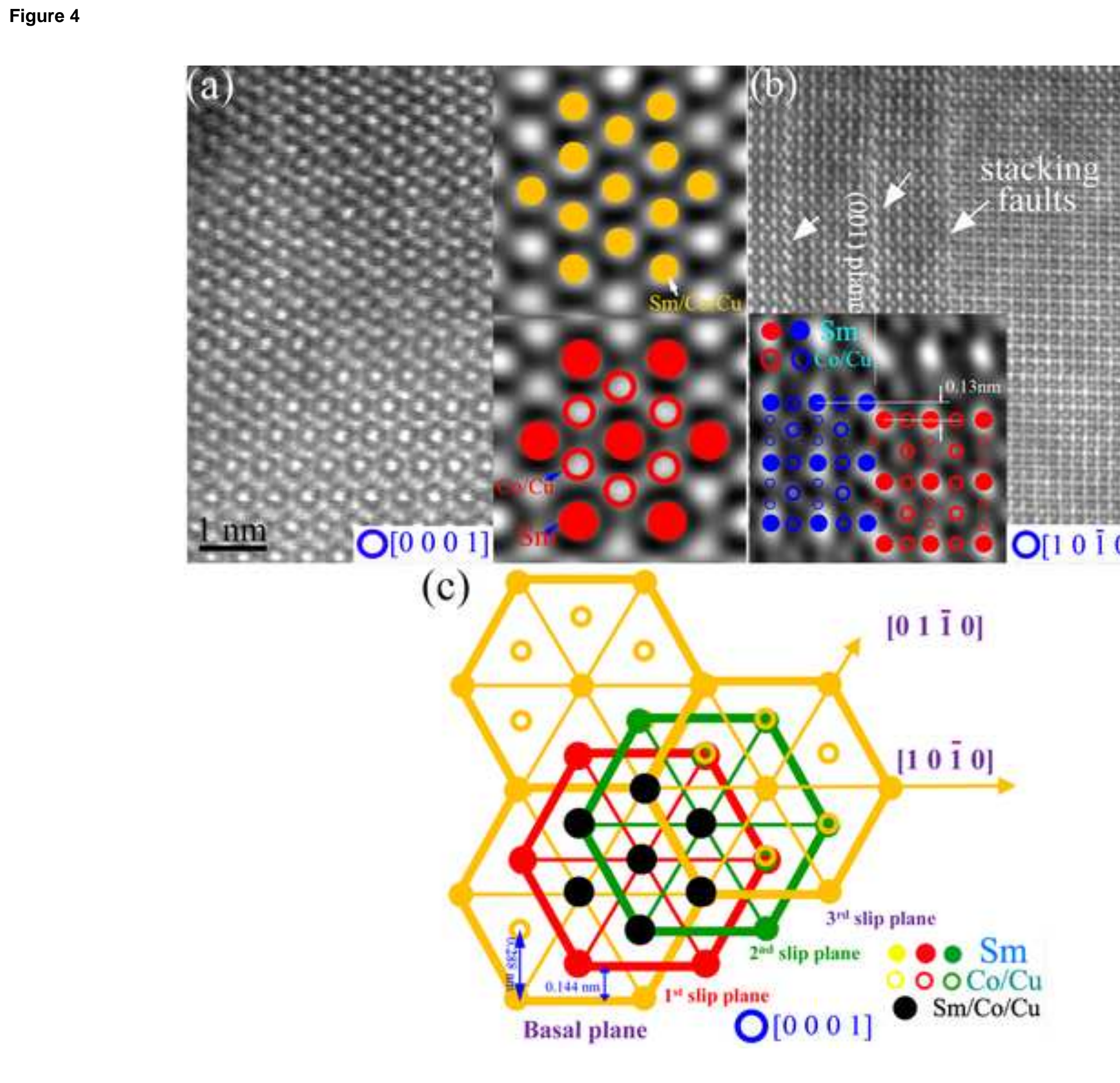

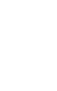

.
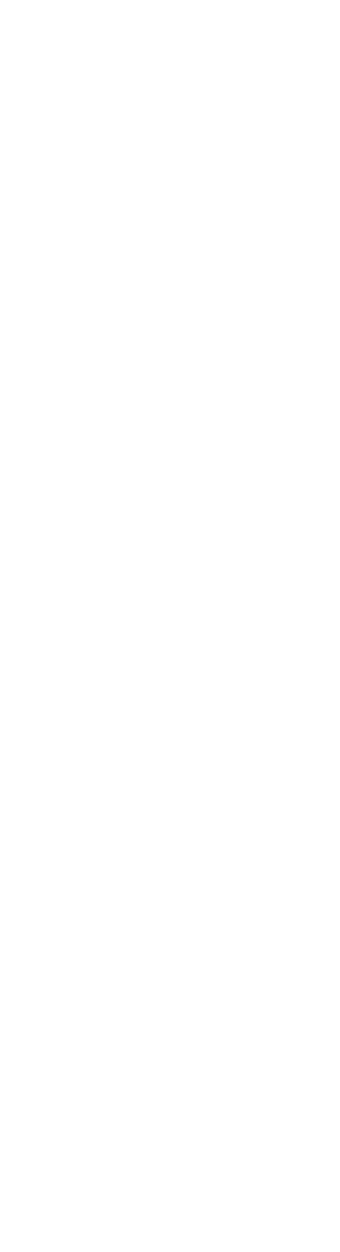

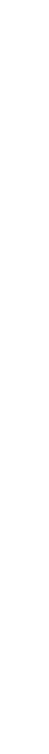

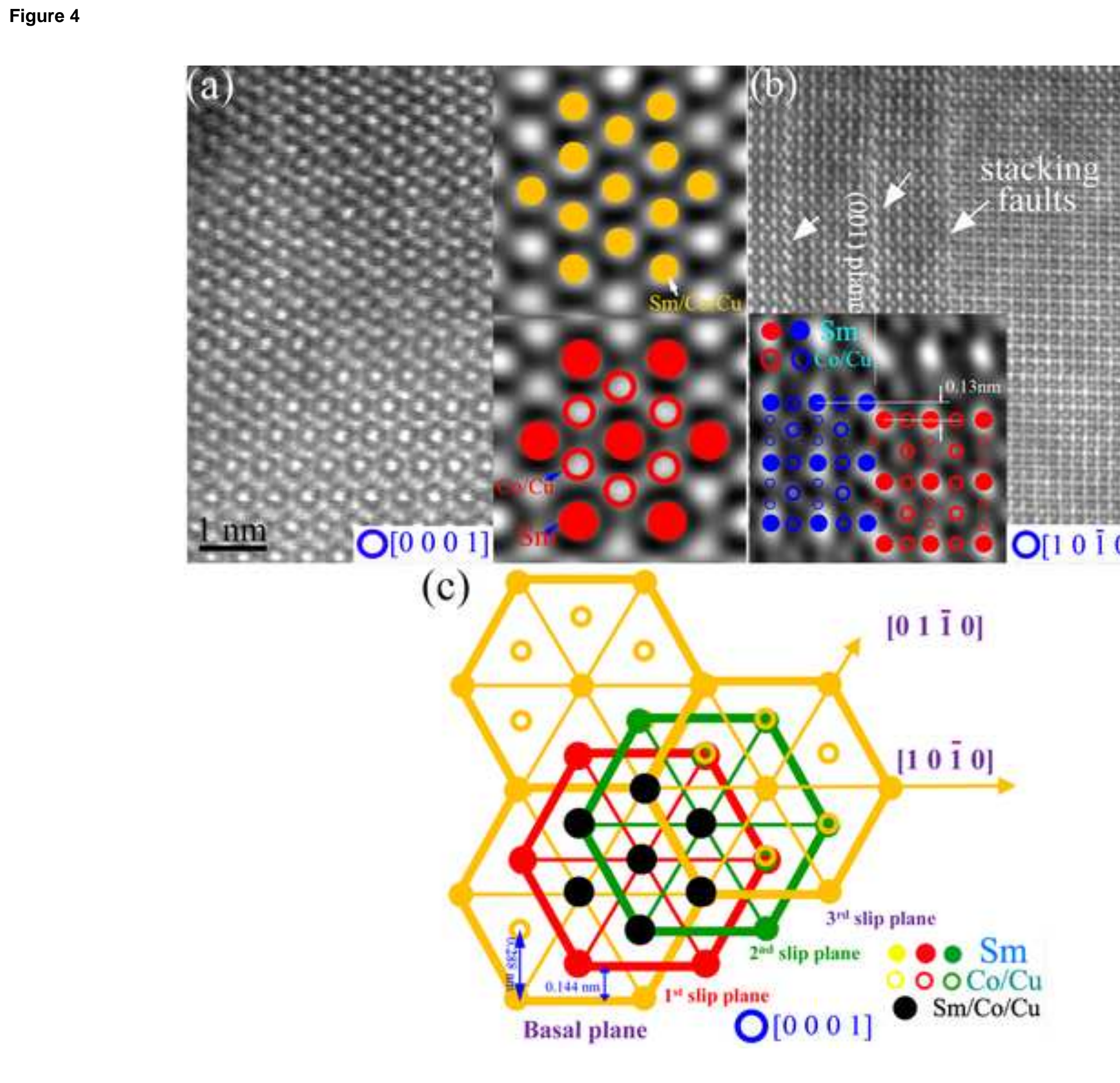

-

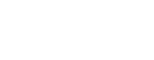

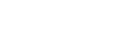

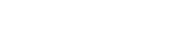

$\sqrt{2}+x^{2}$
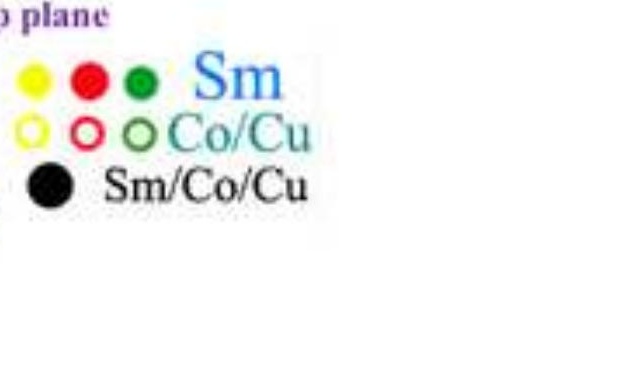


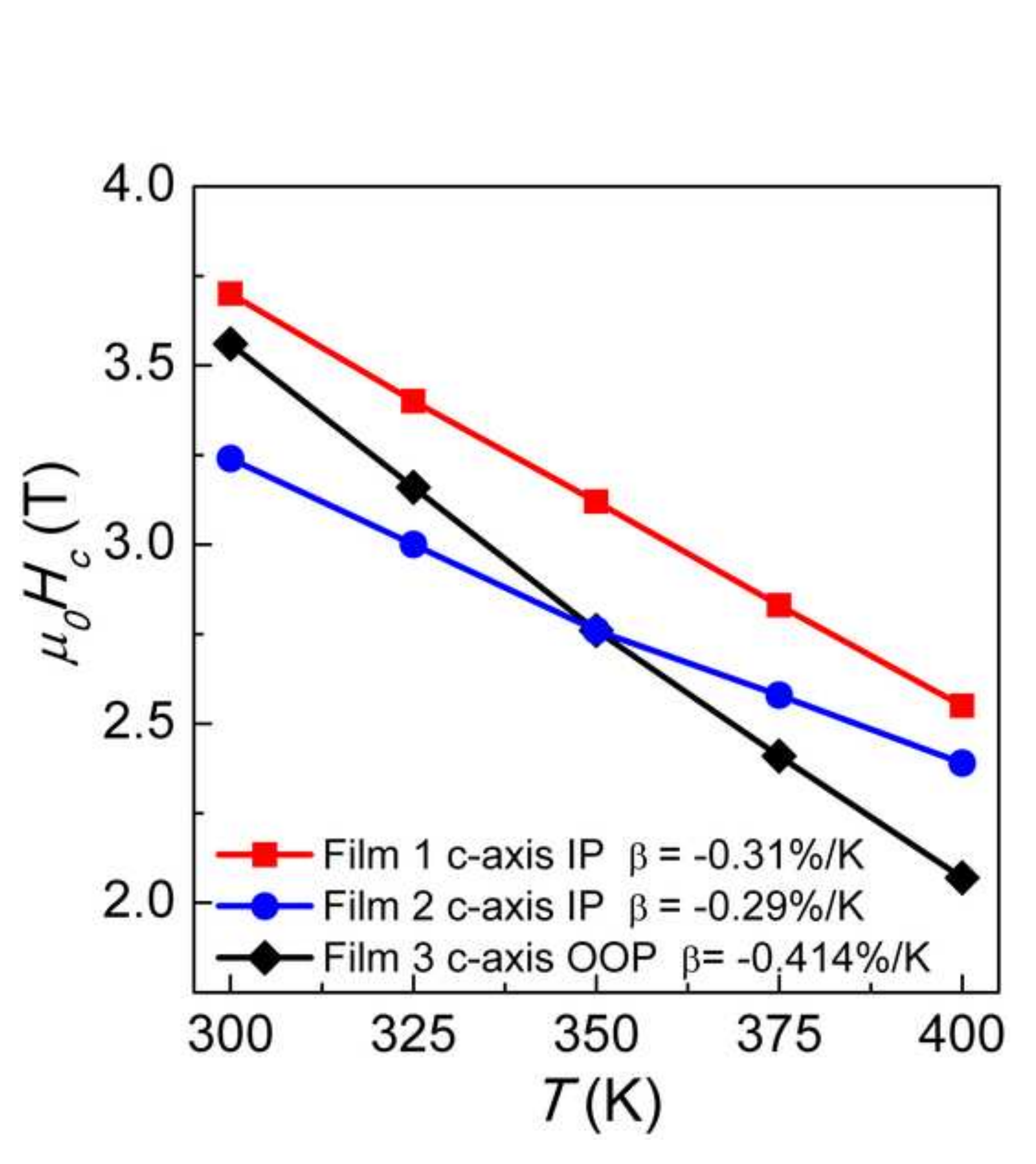

Figure 5

5
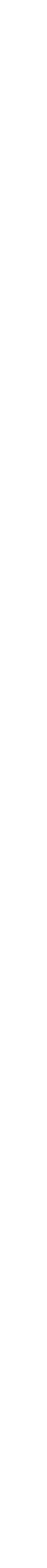


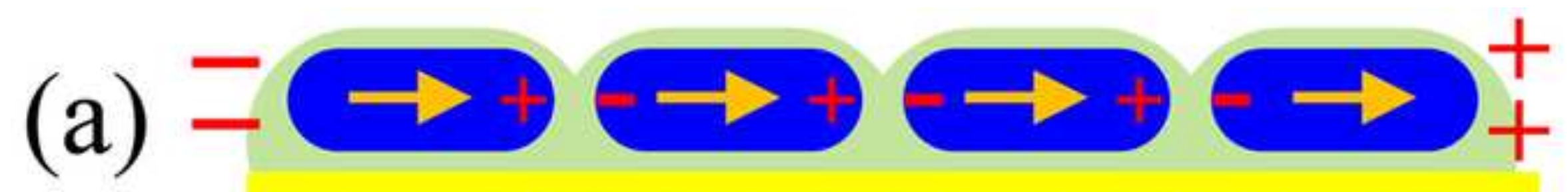

$\mu_{0} \mathrm{H}_{\mathrm{c}}=3.7 \mathrm{~T} \quad \beta=-0.31 \% / \mathrm{k} \quad \alpha=0.14 \quad N_{\text {eff }}=1.2$

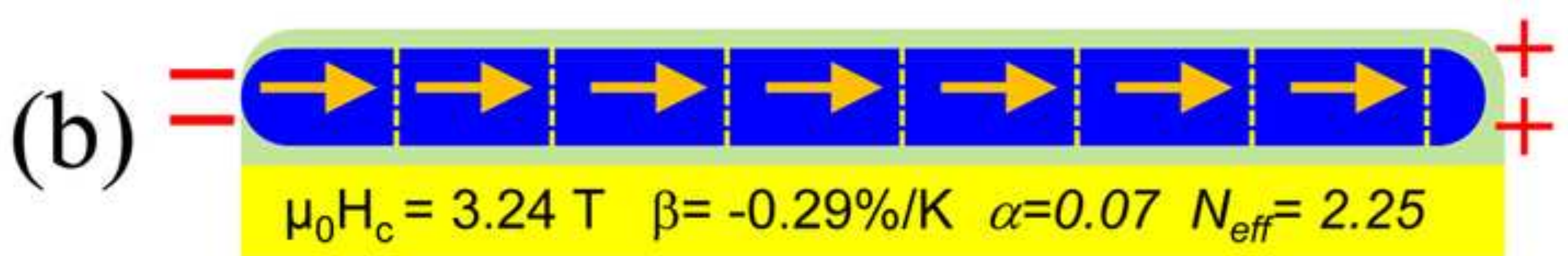

(c)

$++t++++++t+t+$

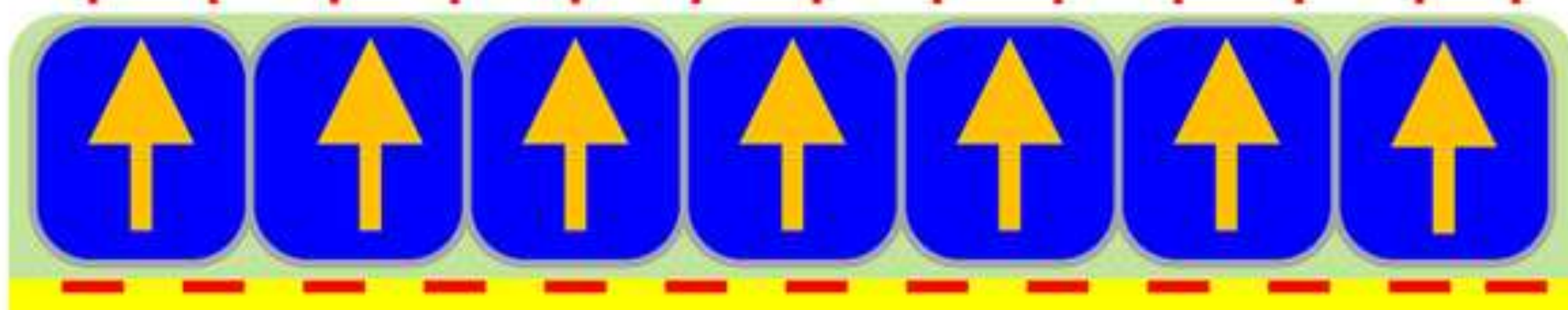

$\mu_{0} H_{c}=3.56 \mathrm{~T} \quad \beta=-0.42 \% / \mathrm{K} \quad \alpha=0.38 \quad N_{\text {eff }}=6.83$ 

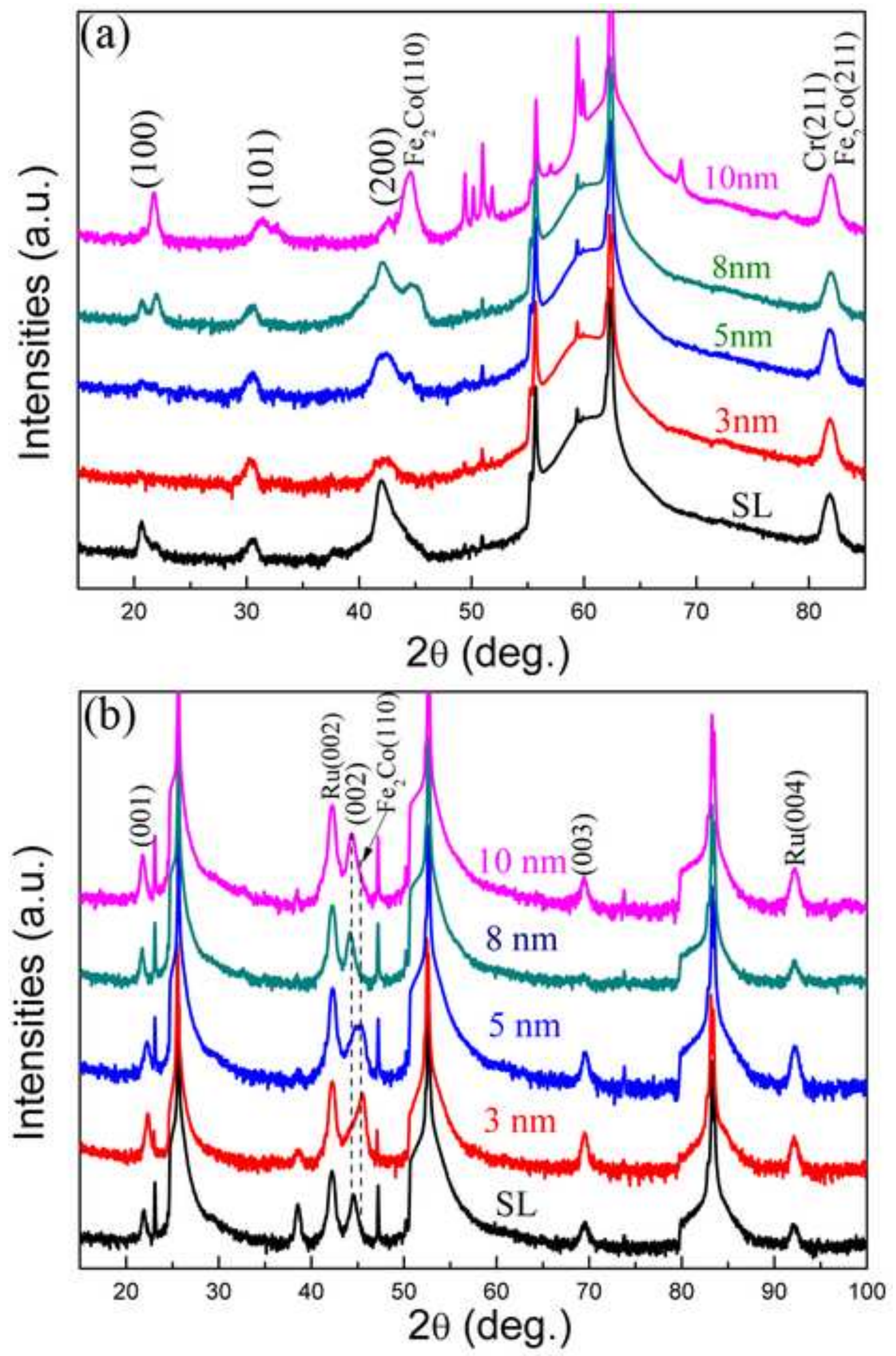

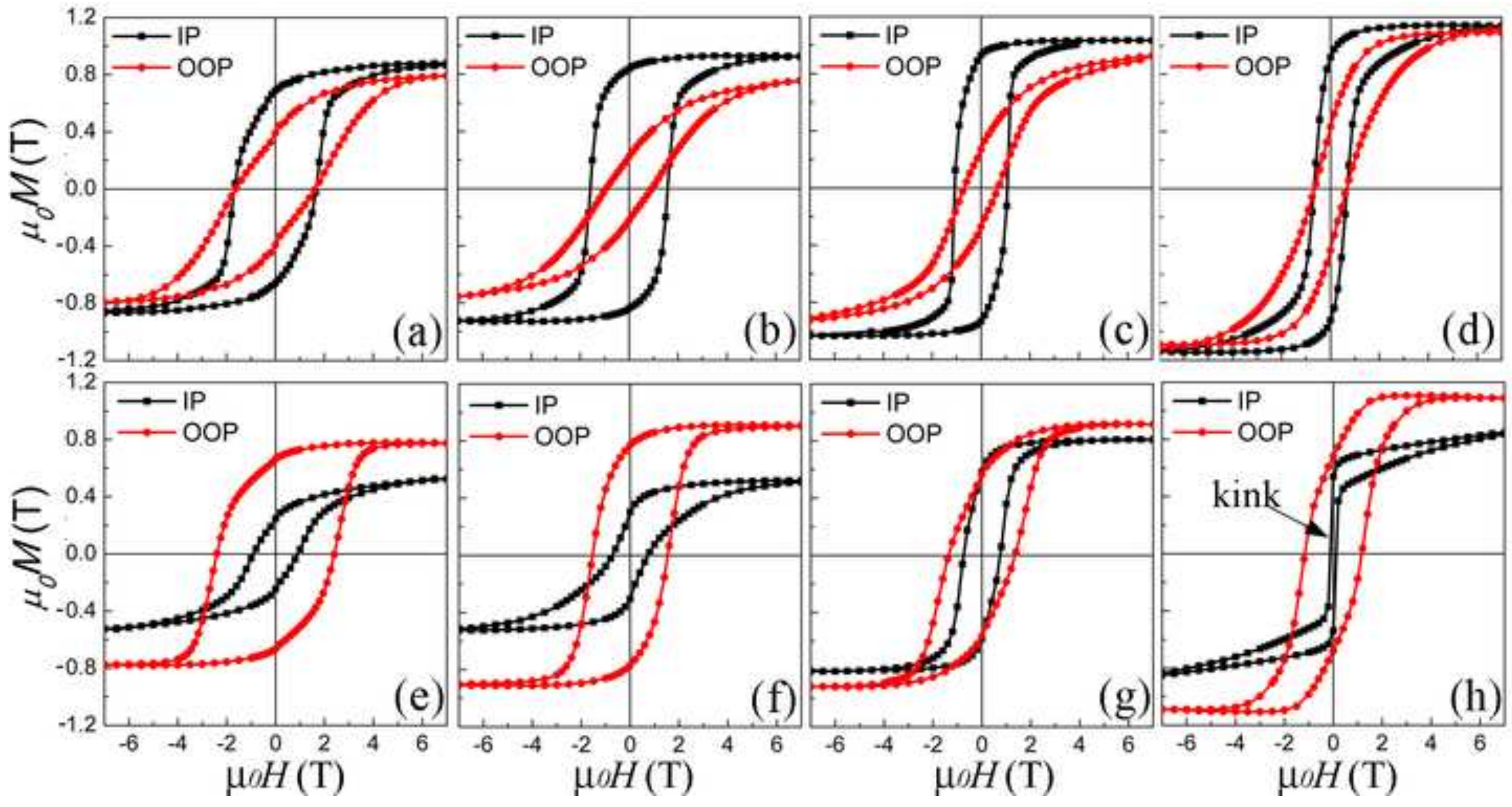

$\frac{\text { (h) }}{6}$ 


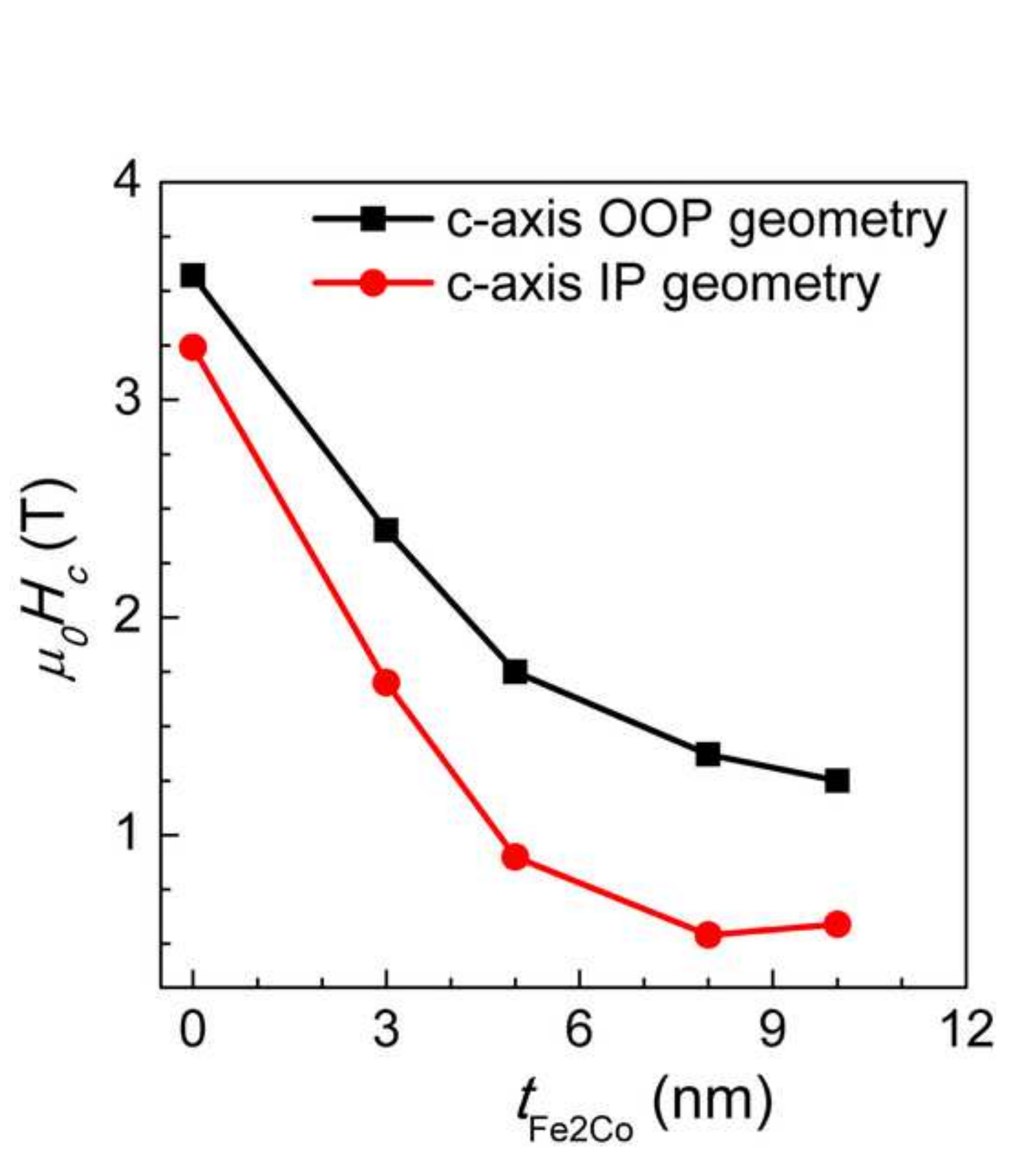

Figure 9

Figure

-

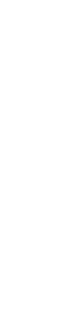

(1)

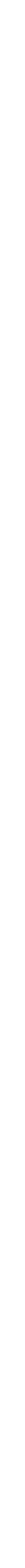

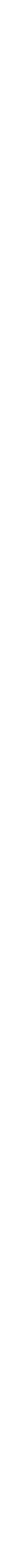




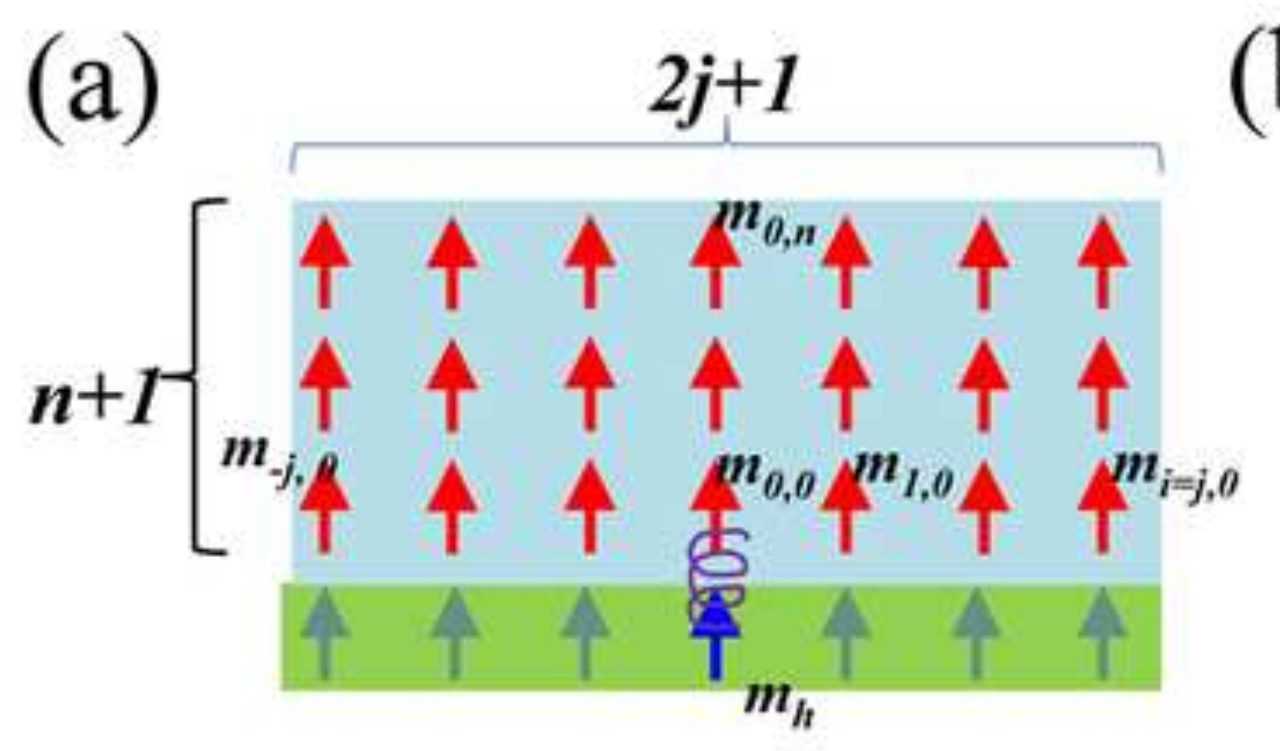

OOP EC geometry (b) $\quad 2 j+1$

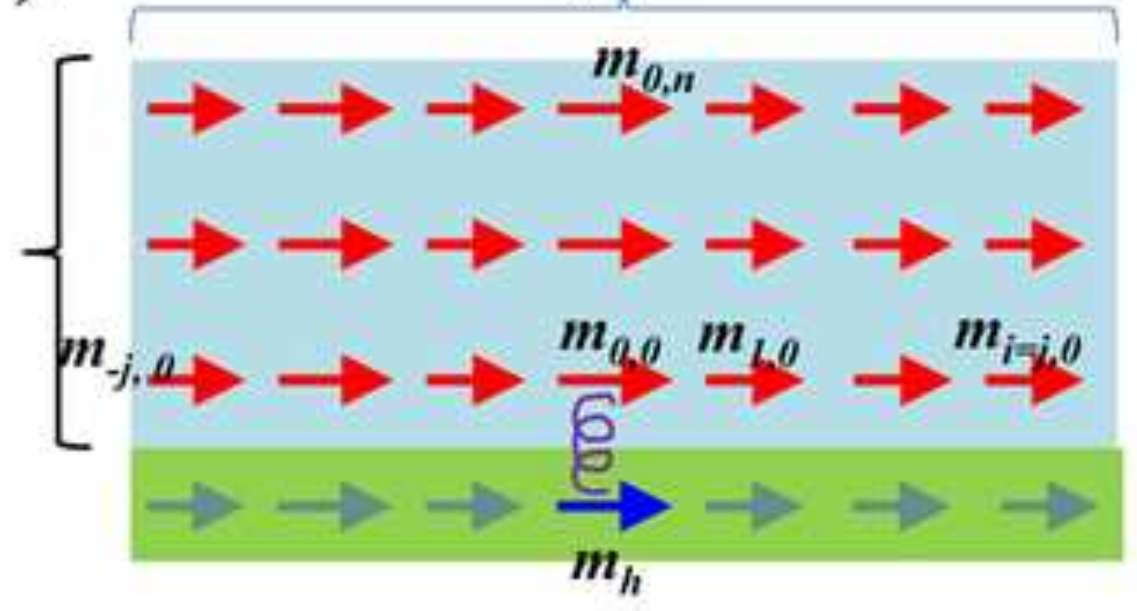

IP EC geometry

(c)

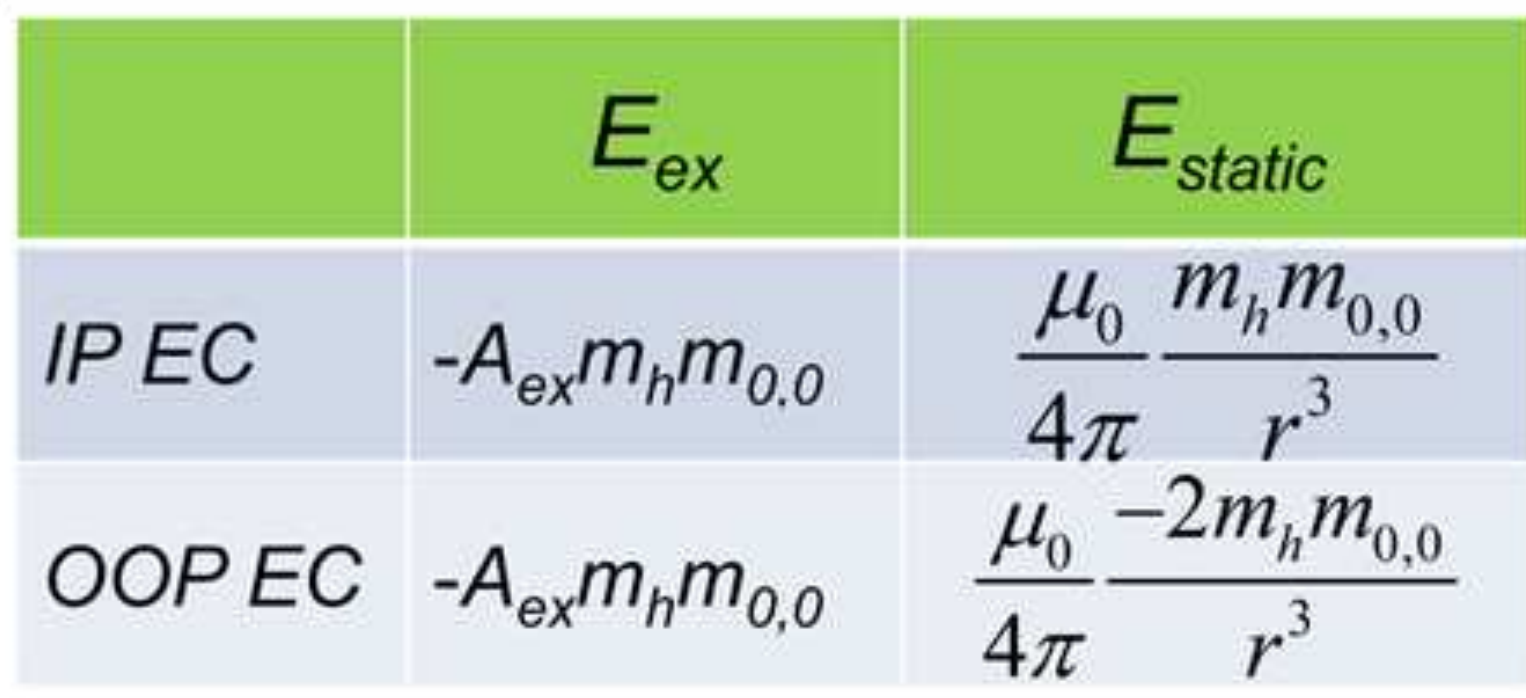


a)

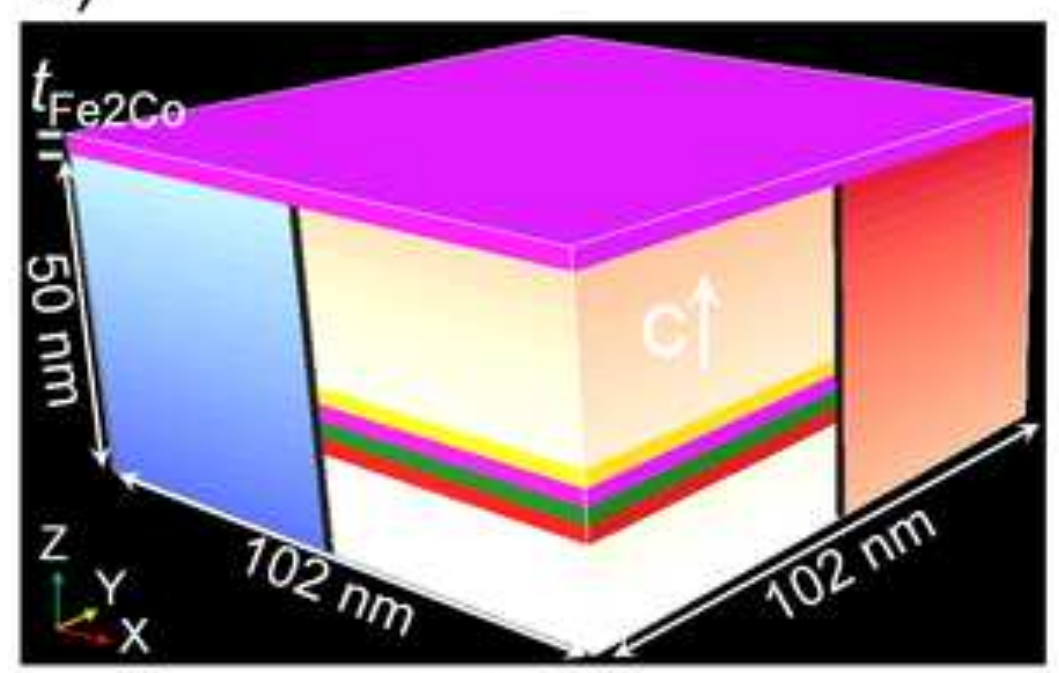

C) ${ }^{8}$
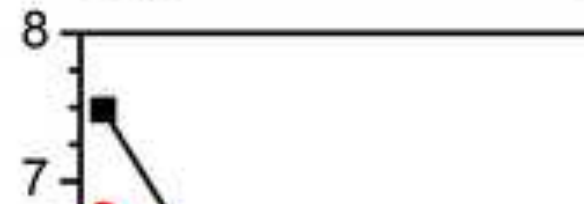

b)
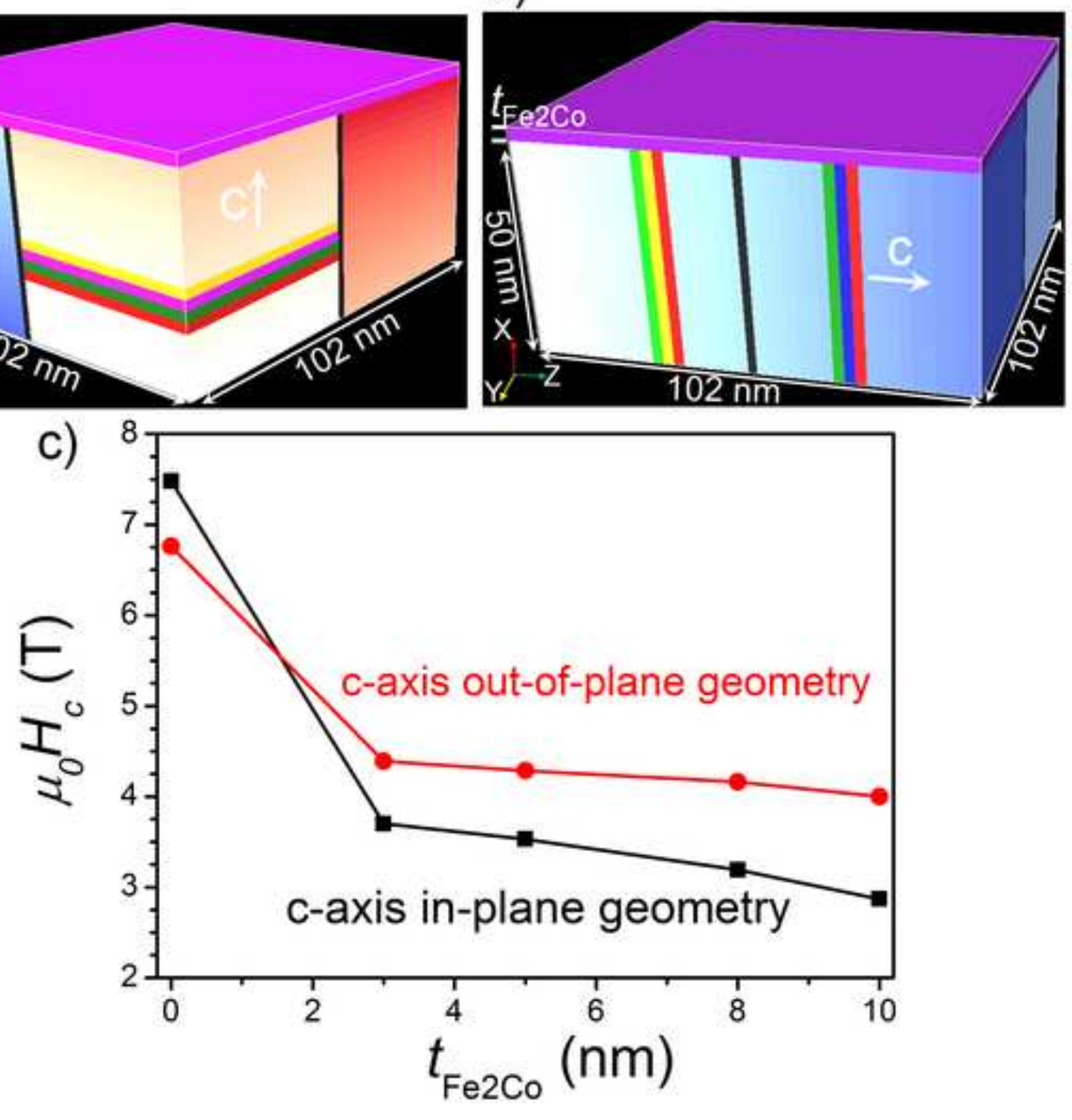


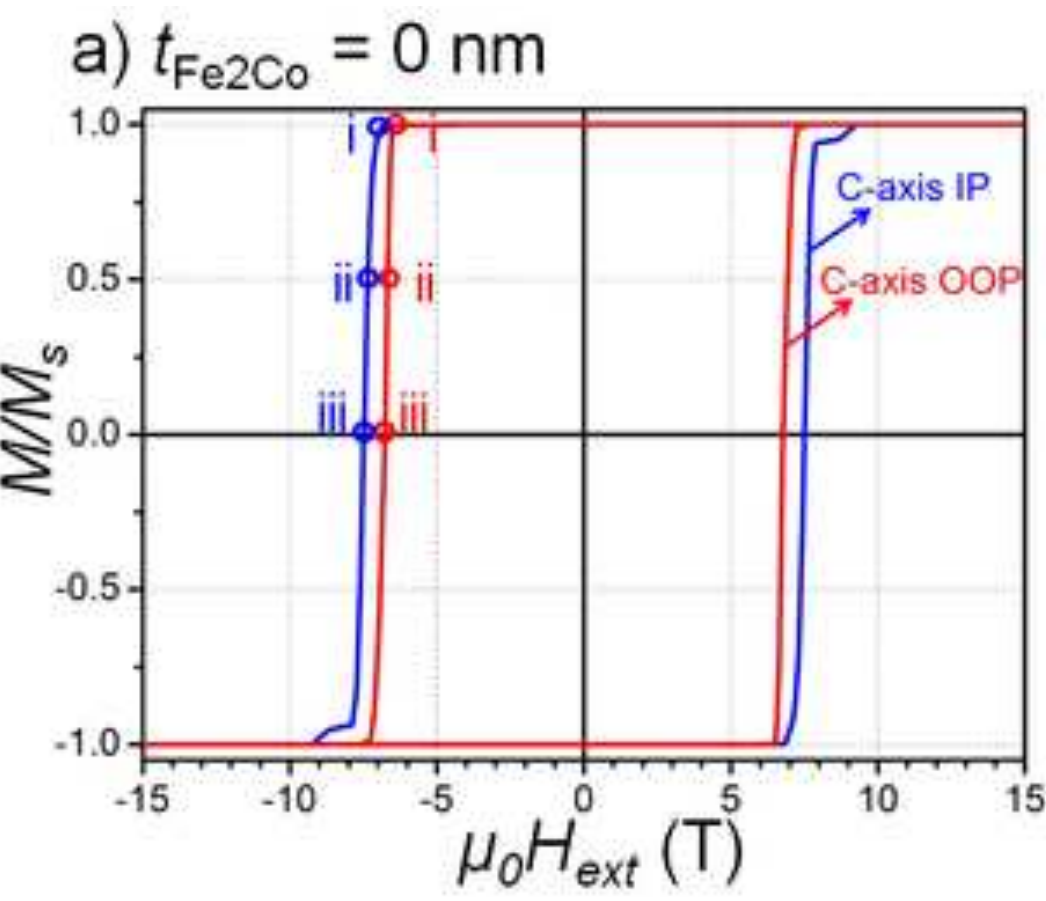

b) c-axis IP
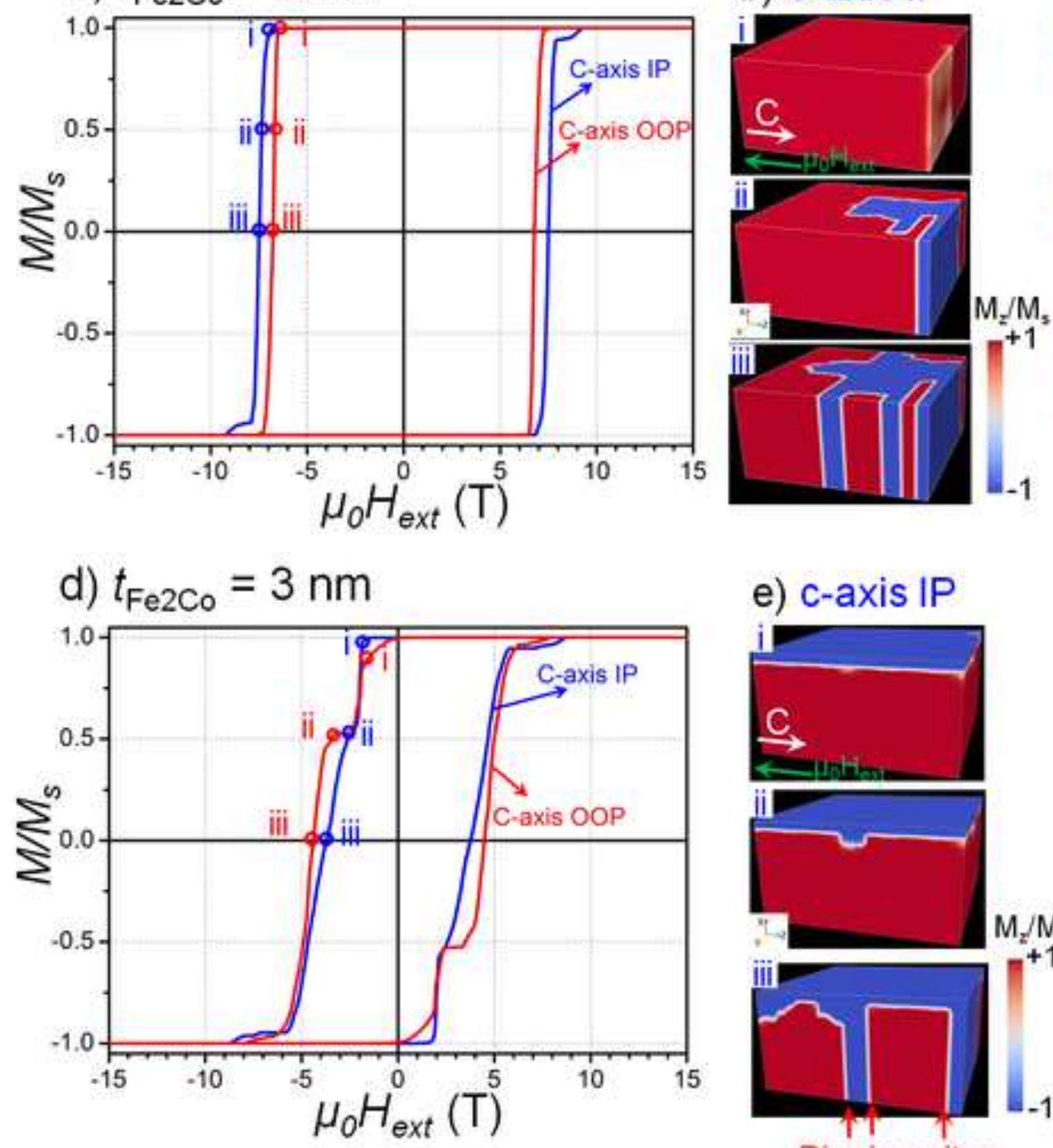

e) c-axis IP

c) c-axis $O O P$
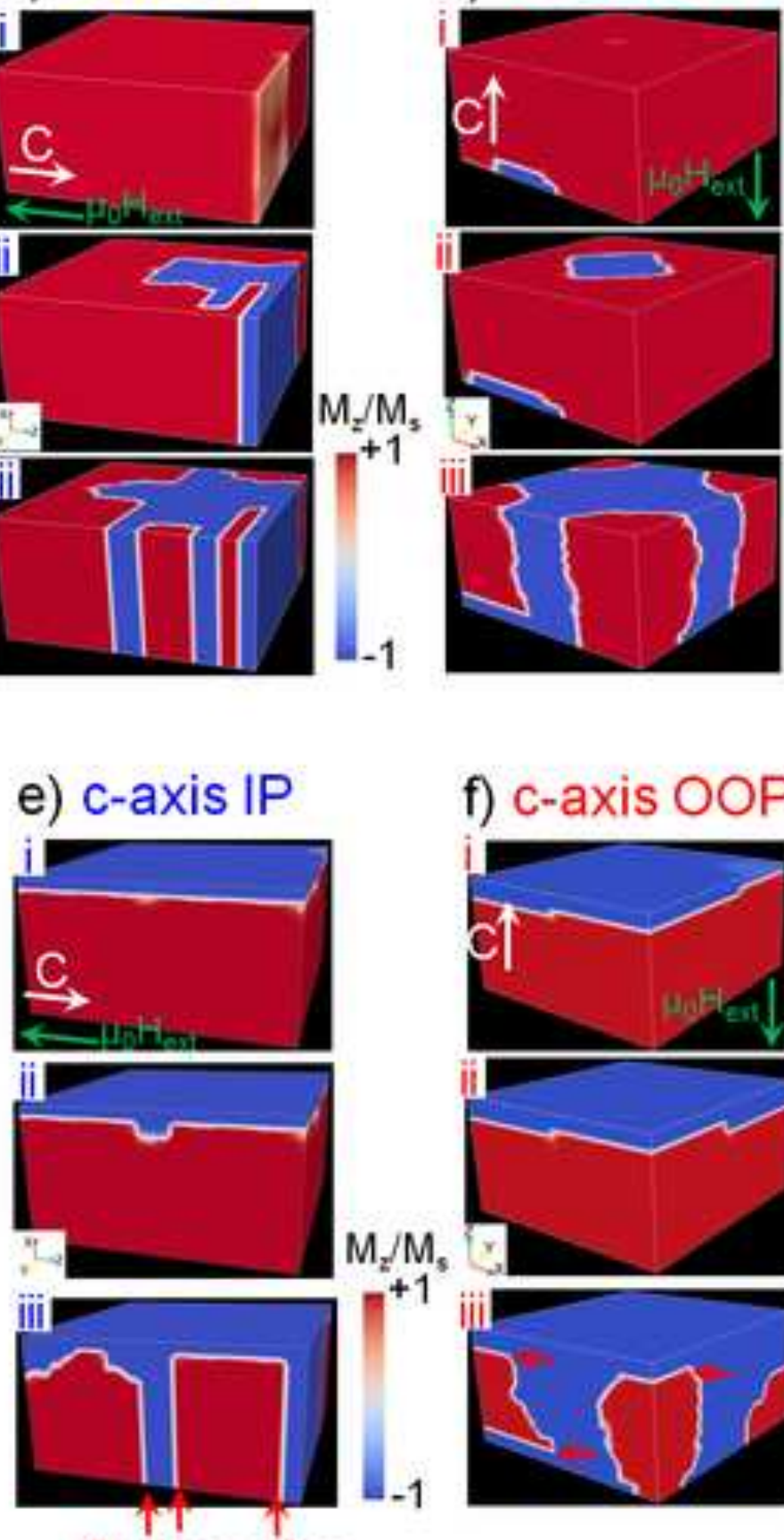

f) C-axis OOP
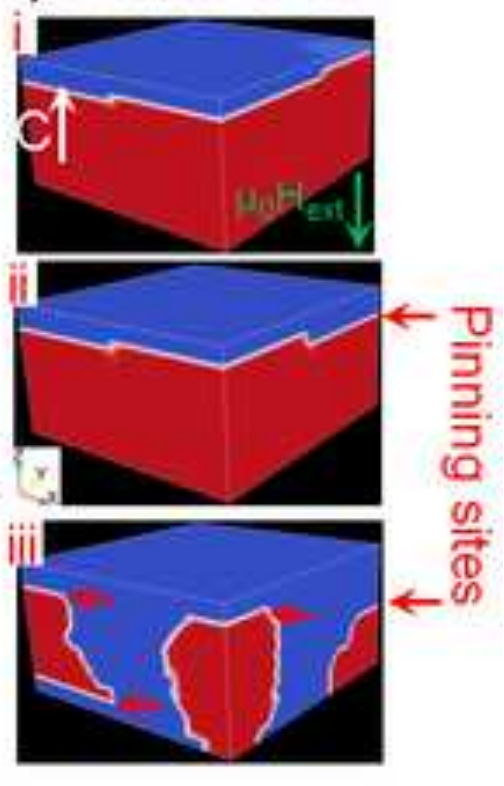

Pinning sites 
Graphical Abstract
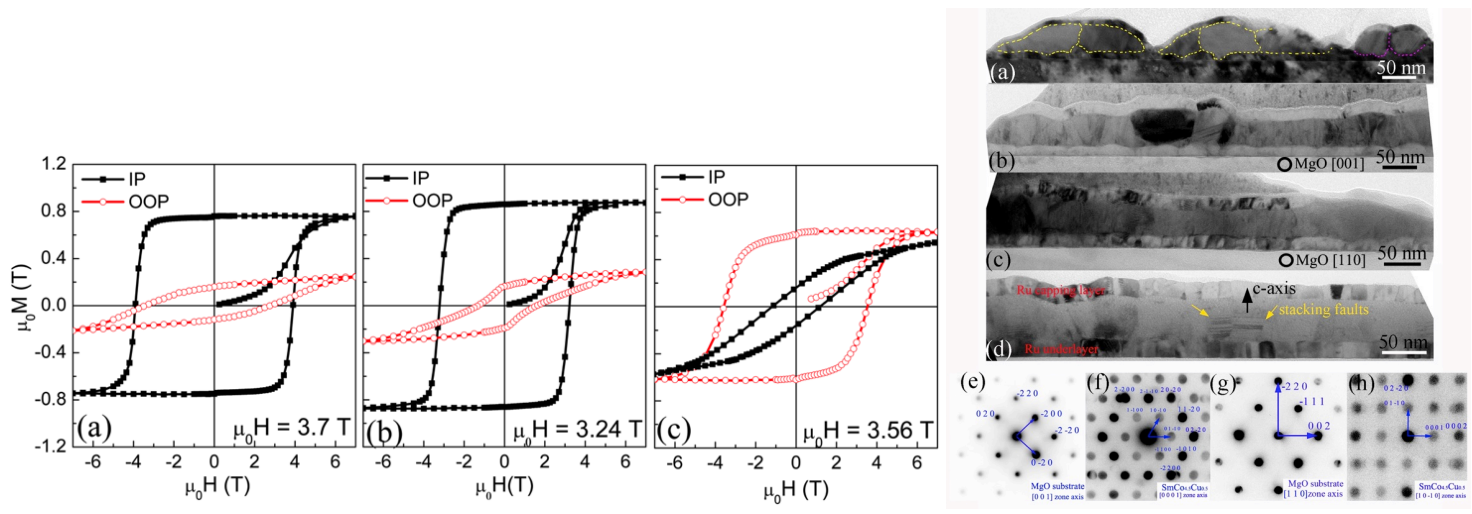